\title{
Influence of Pozzolan, Slag and Recycled Aggregates on the Mechanical and Durability Properties of Low Cement Concrete
}

\author{
Eliana Soldado ${ }^{1, *}$, Ana Antunes ${ }^{1,2}$, Hugo Costa ${ }^{1,2}$, Ricardo do Carmo ${ }^{1,2}$ (D) and Eduardo Júlio ${ }^{2,3}$ (D) \\ 1 ISEC-Polytechnic Institute of Coimbra, 3045-093 Coimbra, Portugal; celia.antunes@isec.pt (A.A.); \\ hcosta@isec.pt (H.C.); carmo@isec.pt (R.d.C.) \\ 2 Civil Engineering Research and Innovation for Sustainability (CERIS), 1049-001 Lisbon, Portugal; \\ eduardo.julio@tecnico.ulisboa.pt \\ 3 Instituto Superior Técnico, Universidade de Lisboa, 1049-001 Lisbon, Portugal \\ * Correspondence: eliana.soldado@isec.pt
}

Citation: Soldado, E.; Antunes, A.; Costa, H.; do Carmo, R.; Júlio, E. Influence of Pozzolan, Slag and Recycled Aggregates on the Mechanical and Durability Properties of Low Cement Concrete. Materials 2021, 14, 4173. https://doi.org/ $10.3390 / \mathrm{ma} 14154173$

Academic Editor: Francisca Puertas

Received: 30 June 2021

Accepted: 23 July 2021

Published: 27 July 2021

Publisher's Note: MDPI stays neutral with regard to jurisdictional claims in published maps and institutional affiliations.

Copyright: (c) 2021 by the authors. Licensee MDPI, Basel, Switzerland. This article is an open access article distributed under the terms and conditions of the Creative Commons Attribution (CC BY) license (https:// creativecommons.org/licenses/by/ $4.0 /)$.

\begin{abstract}
The sustainability of the construction sector demands the reduction of $\mathrm{CO}_{2}$ emissions. The optimization of the amount of cement in concrete can be achieved either by partially replacing it by additions or by reducing the binder content. The present work aims at optimizing the properties of concrete used in the production of reinforced concrete poles for electrical distribution lines, combining the maximization of compactness with the partial replacement of cement by fly ash, natural pozzolans, and electric furnace slags. Natural aggregates were also partially replaced by recycled ones in mixtures with fly ash. Two types of concrete were studied: a fresh molded one with a dry consistency and a formwork molded one with a plastic consistency. The following properties were characterized: mechanical properties (flexural, tensile splitting, and compressive strengths, as well as Young's modulus) and durability properties (capillary water absorption, water penetration depth under pressure, resistance to carbonation, chloride migration, and concrete surface resistivity). The service life of structures was estimated, taking the deterioration of reinforcement induced by concrete carbonation or chloride attack into account. Results revealed that mixtures with fly ash exhibit higher mechanical performance and mixtures with fly ash or pozzolans reveal much higher durability results than the full Portland cement-based mixtures.
\end{abstract}

Keywords: low cement concrete; pozzolan; slag; additions; recycled aggregates; mechanical performance; durability

\section{Introduction}

In recent years, there has been growing concern about environmental sustainability and global warming causes and effects. The construction sector has a very important role in reducing the greenhouse effect and promoting sustainability. It is estimated that, in 2018, cement production reached 3.99 billion tons worldwide [1]. Clinker is responsible for 60 to $65 \%$ of the total emissions of the entire cement production process [2]. The European Cement Association predicts that, with a joint effort by the construction industry, deep $\mathrm{CO}_{2}$ emission cuts can be achieved to lead to carbon neutrality. The same association proposes measures that will lead to a reduction in $\mathrm{CO}_{2}$ emissions of the production process of up to $3.5 \%$, in 2030 , and $8 \%$, in 2050 . The proposed strategy aims at the use of zerocarbon materials, such as natural, waste materials and by-products from other industries, such as pozzolans, fly ash, granulated slag, silica fume, and others, resulting in a good example of industrial symbiosis [2]. Additionally, the replacement of natural aggregates with recycled aggregates is a measure that promotes the sustainability and the circular economy, minimizing the environmental impact and excessive extraction of non-renewable resources [3]. This replacement is an urgent measure, as the construction sector is a major consumer of natural resources and the global aggregate production went from 21 billion tons in 2007 to 40 billion tons in 2014 [4]. 
Optimizing concrete's eco-efficiency should not harm its mechanical and durability properties. Previous studies prove that it is possible to produce concrete with low cement content and good mechanical performance $[5,6]$. Concrete's durability can be enhanced by optimizing the packing density, which is highly influenced by the distribution and the size of the particles, reducing the space between them and obtaining a closed and less permeable matrix, also reducing the space needed to be filled with hydration products [6-9]. This process can be simplified through the addition of superplasticizers, reducing the amount of water required by the mixture and thus avoiding water in excess, which is quite harmful to mixtures' performance [5,10-14].

The most commonly used additions in cement replacement are silica fume, fly ash, ground granulated blast furnace slag, metakaolin, and limestone filler, amongst other industrial by-products. Most studies focus on the addition of fly ash (with a recommended replacement rate of $15-20 \%$, but some studies guarantee up to $50 \%$ [15-18]) due to its proven benefits in workability, mechanical performance and economy $[5,15,16,18,19]$. Being a pozzolanic addition, it has a slow initial reaction and maximum strength at older ages $[5,11]$. Regarding durability, the literature highlights the good results of fly ash addition in resistance to chlorides, permeability and porosity [15,20-22]. On the contrary, its negative effect on carbonation-induced corrosion is recognized, since it is a sensitive addition and leads to a loss of $\mathrm{pH}$ in concrete, suggesting, many times, that it should be used combined with limestone filler $[6,11,23]$. However, its announced extinction in developed countries underlines the need to develop sustainable and efficient alternatives, such as natural pozzolans or by-products, like industrial slags.

In the last decade, research on the properties of concrete with coarse recycled concrete aggregates, as substitutes for coarse natural aggregates, has increased substantially [24-29]. However, the practical use of the recycled aggregates in concrete is still mostly nonstructural [4], lacking studies about their variability and reliability, since they are more heterogeneous than natural aggregates [24]. Its use is generally hampered by the higher porosity and reduced stiffness, which also depends on the original concrete quality. These factors may not highly affect mechanical strength for current concrete strength, but may interfere with other parameters, such as Young's modulus [30]. Nevertheless, the new versions of concrete codes, under development, already contemplate the inclusion of recycled aggregates in concrete, enabling their wide and regulated use [30,31]. The general conclusion from the literature is that there is a decrease in durability with the amount of recycled aggregates included [32]. Though, it is possible to fill this gap by including additions, such as fly ash and silica fume to the concrete [28,33-36]. The aim is to make the matrix more closed and less permeable to aggressive agents.

The problems associated with the durability of the reinforced concrete structures, as well as concrete poles, are related with the corrosion risk of the rebars due to permanent exposure to very aggressive environments, such as chloride ions and carbonation. Chloride induced corrosion is one of the most frequent causes of concrete deterioration [33,37], compromising its service life and the safety of the structures, as its load capacity is severely decreased [38-40]. Once corrosion starts, phenomena such as concrete cracking, delamination, loss of the steel-concrete bond and loss of the reinforcement section, occur. These phenomena lead to very high repair costs and reduced service life [41,42]. Although the majority of reinforced concrete structures are design to have a service life of 50-100 years, many require sooner intervention and, in severe environments, it may be difficult to avoid steel corrosion within typical service periods of 15-20 years [40,43]. The analysis of capillary absorption in concrete is important because it is through this capillary network that water and aggressive agents are dissolved and transported to the concrete matrix. Carbon dioxide is diffused through this network and dissolved in pore water, forming carbonic acid [44-46], creating a carbonation front that reduces the concrete alkalinity and creates the corrosion risk. In general, $2 / 3$ of the concrete structures are exposed to this aggressive agent, continuously or cyclically [47]. In the literature, durability is usually analyzed in terms of resistance to carbonation, chlorides and permeability $[15,16,20,43]$. However, that 
analysis is available for concrete with current formulation, but it has not been studied in depth for concretes with high compactness, low cement dosages and specific additions, such as natural pozzolan and electric furnace slag, instead of fly ash.

In this sense, this work is part of a research project that aims to improve the formulation, eco-efficiency, performance and durability of a precast reinforced concrete used to produce poles for the electric distribution lines. Its main goal is to develop eco-efficient concrete solutions, combining high compactness with partial cement replacement by natural additions and by waste by-products from other industries and with the inclusion of recycled concrete aggregates. This study intended to develop the following points: (i) assess the influence of the maximum increase in compactness without loss of the required workability; (ii) analyze the effect of different additions (fly ash, natural pozzolan and ground electric furnace slag) as cement substitutes; (iii) evaluate the combination between the considered additions and high compactness in the mechanical and durability properties of concrete; (iv) study the correlation between those properties, namely between different durability tests (capillary absorption, accelerated carbonation, electrical resistivity and chloride ion migration); (v) predict the service life for different exposures to chloride and carbonation ingression. Currently, the production of concrete poles is divided into two types: one with dry consistency for fresh molded concrete (BT series); and other with plastic consistency concrete (MT series), for formwork molded concrete. The mixtures considered as a reference are those currently produced in the industry, with cement content between 360 and $400 \mathrm{~kg} / \mathrm{m}^{3}$. For the optimization study, the quantity of binder was established at $350 \mathrm{~kg} / \mathrm{m}^{3}$, in order to guarantee the workability and cohesion of the fresh mixtures [6], and the cement content replaced by additions of fly ash, natural pozzolans and electric furnace slag was up to $50 \%$. In the mixtures with fly ash, $20 \%$ of the natural aggregates were replaced by recycled concrete aggregates, from industrial waste from the poles production. The presented mixtures are based on previous extensive study performed in mortar matrices, evaluating mechanical and durability performance [48]. Based on the results of that study, the optimized mixtures of each series were then reproduced on concrete, as above mentioned, in which the mechanical properties and durability were evaluated. For instance, when pozzolans are considered, carbonation was not performed in concrete, since it presents reduced resistance in mortar matrices; when electric furnace slags are added, the chlorides migration was not characterized in concrete, since it presents reduced chloride resistance in mortar matrices.

\section{Materials and Methods}

The optimized concrete mixtures with low cement content were formulated and compared with reference fully cement-based mixtures, in order to evaluate the mechanical performance and durability of the optimized concretes. In these mixtures, the following powder materials were selected: CEM II-A/L 42.5R (C); F-type fly ash (FA); Cape Verde natural pozzolans (Poz) and ground electric furnace slag (Slag). The corresponding density values, in $\mathrm{kg} / \mathrm{dm}^{3}$, were characterized: $3.08 ; 2.30 ; 2.30$ and 3.83 . The chemical composition of the powders is presented in Table 1 . The pozzolanic activity indexes, assessed at 90 days [49], resulted in the following values: $0.88 ; 0.87 ; 0.70$, respectively for fly ash, natural pozzolans and electric furnace slag. The following aggregates were used in the mixtures: fine siliceous sand $0 / 1 \mathrm{~mm}$; medium siliceous sand $0 / 4 \mathrm{~mm}$; crushed limestone gravels with two size fractions, $2 / 5 \mathrm{~mm}$ and $6 / 12 \mathrm{~mm}$; recycled concrete aggregates (RA), from the concrete poles production waste, with two different size fractions (RA1/8 mm, for BT mixtures; RA4/16 mm, for MT mixtures), which were incorporated in $20 \%$ of volume replacement. The following densities were characterized for the aggregates, in $\mathrm{kg} / \mathrm{dm}^{3}: 2.63$ for sands, 2.66 for gravels and 2.30 for RA. The RA were characterized with absorption of $4 \%$. Tap water from public supply and two types of admixtures were used: HE200P (HE), a water reducer and hardening accelerator for molded cohesive concrete with dry consistency, with density of $1.17 \mathrm{~kg} / \mathrm{dm}^{3}$, favoring a better dispersion for the BT 
mixtures; Sky526 (SKY), an ether-polycarboxylate based superplasticizer with a density of $1.06 \mathrm{~kg} / \mathrm{dm}^{3}$, to increase plasticity and reduce the water content for the MT mixtures.

Table 1. Chemical composition of the powders, characterized by XRF (X-ray fluorescence).

\begin{tabular}{|c|c|c|c|c|}
\hline Test & $\mathrm{C}$ & FA & Poz & Slag \\
\hline$\% \mathrm{SiO}_{2}$ & 17.38 & 54.0 & 46.18 & 16.10 \\
\hline$\% \mathrm{Al} 2 \mathrm{O}_{3}$ & 4.67 & 22.0 & 16.44 & 11.08 \\
\hline$\% \mathrm{Fe}_{2} \mathrm{O}_{3}$ & 2.91 & 8.50 & 6.30 & 31.75 \\
\hline$\% \mathrm{CaO}$ & 62.00 & 6.00 & 6.11 & 27.31 \\
\hline$\% \mathrm{MgO}$ & 1.38 & 1.60 & 3.09 & 5.71 \\
\hline$\% \mathrm{SO}_{3}$ & 2.96 & 0.00 & 0.01 & 0.31 \\
\hline$\% \mathrm{~K} 2 \mathrm{O}$ & 0.54 & 1.60 & 4.19 & 0.02 \\
\hline$\% \mathrm{Na}_{2} \mathrm{O}$ & 0.09 & 1.00 & 5.80 & 0.07 \\
\hline$\% \mathrm{TiO}_{2}$ & - & 1.20 & 1.91 & 0.67 \\
\hline$\% \mathrm{P}_{2} \mathrm{O}_{5}$ & - & 0.80 & 0.41 & 0.50 \\
\hline$\% \mathrm{MnO}$ & - & $<0.3$ (1.q) & 0.26 & 3.53 \\
\hline$\% \mathrm{SrO}$ & - & - & 0.08 & 0.03 \\
\hline$\% \mathrm{CuO}$ & - & - & - & 0.04 \\
\hline$\% \mathrm{~V}_{2} \mathrm{O}_{5}$ & - & - & - & 0.11 \\
\hline$\% \mathrm{Cr}_{2} \mathrm{O}_{3}$ & - & - & - & 1.92 \\
\hline$\% \mathrm{ZrO}_{2}$ & - & - & - & 0.03 \\
\hline$\% \mathrm{Nb}_{2} \mathrm{O}_{5}$ & - & - & - & 0.03 \\
\hline$\% \mathrm{BaO}$ & - & - & - & 0.12 \\
\hline$\% \mathrm{Cl}$ & 0.05 & - & - & 0.04 \\
\hline$\% \mathrm{~F}$ & - & - & - & 0.65 \\
\hline LOI (\%) & 8.00 & 3.90 & 8.33 & -2.08 \\
\hline
\end{tabular}

Regarding concrete mixtures, two types of consistency were considered and divided in two series, BT-dry consistency and MT-plastic consistency. The mixtures were formulated based on the method proposed by Lourenço et al. [50] and developed by Costa [51], which parameters were adopted in order to minimize the cement dosage; however, maximizing compactness, taking a maximum amount of binder of $350 \mathrm{~kg} / \mathrm{m}^{3}$ into account. The corresponding amount of cement was between 200 to $250 \mathrm{~kg} / \mathrm{m}^{3}$, depending on the selected additions and on the target strength of circa $50 \mathrm{MPa}$, at 56 days. The resulting proportions of additions varied from $29 \%$ to $43 \%$ for those mixtures. Admixtures' dosages were adjusted to achieve the target consistency of each mixture, whose content in relation to the cement weight varied between $2.9 \%$ and $4.5 \%$ in BT and between $0.7 \%$ and $1.1 \%$ in MT series. The concrete was mixed with pre-wetting of recycled aggregates, with around $30 \%$ of the total water, waiting about $5 \mathrm{~min}$, preventing the admixture from being partially absorbed with water. Then, the remaining solid constituents were placed and mixed, then the remaining water with the diluted admixture was added, mixing until obtaining the pre-defined homogeneity and consistency. The molds were filled and compacted with the vibrating table, being the compacting energy low in MT mixtures and high in BT mixtures.

Concrete formulations are presented in Table 2, together with water/cement ratio $(\mathrm{W} / \mathrm{C})$, water/binder ratio (W/B) and the compactness of each mixture, and compared with the two reference mixtures, BTref and MTref, which have current design parameters of prefabrication concrete company. The air content was targeted to $2.0 \%$ in BT and $1.5 \%$ in MT mixtures. The effective water of the mixture is calculated from the fluid part of the mixture which, in turn, depends on the established compactness. The absorption water is related to recycled aggregates and with the corresponding amount of water they absorb, which was added taking into account an initial absorption of $4 \%$ (previously characterized). 
Table 2. Constituents proportioning and formulation parameters of the studied concrete mixtures.

\begin{tabular}{|c|c|c|c|c|c|c|c|c|c|c|}
\hline Constituents & BTref & BT200-FA & $\begin{array}{l}\text { BT200- } \\
\text { FA-RA }\end{array}$ & $\begin{array}{l}\text { BT200- } \\
\text { Poz }\end{array}$ & $\begin{array}{l}\text { BT250- } \\
\text { Slag }\end{array}$ & MTref & $\begin{array}{c}\text { MT250- } \\
\text { FA }\end{array}$ & $\begin{array}{l}\text { MT250- } \\
\text { FA-RA }\end{array}$ & $\begin{array}{c}\text { MT250- } \\
\text { Poz }\end{array}$ & $\begin{array}{l}\text { MT250- } \\
\text { Slag }\end{array}$ \\
\hline$C\left(\mathrm{~kg} / \mathrm{m}^{3}\right)$ & 400 & 200 & 200 & 200 & 250 & 360 & 250 & 250 & 250 & 250 \\
\hline $\mathrm{FA}\left(\mathrm{kg} / \mathrm{m}^{3}\right)$ & - & 150 & 150 & - & - & - & 100 & 100 & - & - \\
\hline $\operatorname{Poz}\left(\mathrm{kg} / \mathrm{m}^{3}\right)$ & - & - & - & 150 & - & - & - & - & 100 & - \\
\hline Slag $\left(\mathrm{kg} / \mathrm{m}^{3}\right)$ & - & - & - & - & 100 & - & - & - & - & 100 \\
\hline $\mathrm{HE}\left(\mathrm{kg} / \mathrm{m}^{3}\right)$ & - & 7.0 & 9.1 & 7.5 & 7.5 & - & - & - & - & - \\
\hline Sky $\left(\mathrm{kg} / \mathrm{m}^{3}\right)$ & - & - & - & - & - & 2.2 & 1.8 & 2.5 & 2.5 & 2.3 \\
\hline $\mathrm{W}_{\mathrm{eff}}{ }^{1}\left(\mathrm{~kg} / \mathrm{m}^{3}\right)$ & 160 & 109 & 112 & 114 & 113 & 173 & 143 & 143 & 143 & 143 \\
\hline $\mathrm{W}_{\mathrm{abs}}{ }^{2}\left(\mathrm{~kg} / \mathrm{m}^{3}\right)$ & - & - & 13 & - & - & - & - & 13 & - & - \\
\hline $\mathrm{S} 0 / 1\left(\mathrm{~kg} / \mathrm{m}^{3}\right)$ & - & 402 & 230 & 398 & 430 & - & 270 & 221 & 270 & 286 \\
\hline $\mathrm{S} 0 / 4\left(\mathrm{~kg} / \mathrm{m}^{3}\right)$ & 923 & 403 & 941 & 399 & 431 & 773 & 632 & 579 & 632 & 671 \\
\hline $\mathrm{C} 2 / 5\left(\mathrm{~kg} / \mathrm{m}^{3}\right)$ & 898 & 1144 & 368 & 1138 & 1120 & 586 & 197 & 440 & 197 & 195 \\
\hline $\mathrm{C} 5 / 12\left(\mathrm{~kg} / \mathrm{m}^{3}\right)$ & - & - & - & - & - & 457 & 795 & 272 & 795 & 787 \\
\hline $\mathrm{RA} 1 / 8\left(\mathrm{~kg} / \mathrm{m}^{3}\right)$ & - & - & 336 & - & - & - & - & - & - & - \\
\hline $\mathrm{RA} 4 / 16\left(\mathrm{~kg} / \mathrm{m}^{3}\right)$ & - & - & - & - & - & - & - & 329 & - & - \\
\hline $\begin{array}{c}\text { Aggregates } \\
\left(\mathrm{kg} / \mathrm{m}^{3}\right)\end{array}$ & 1822 & 1949 & 1873 & 1935 & 1981 & 1816 & 1894 & 1841 & 1894 & 1939 \\
\hline $\mathrm{W} / \mathrm{C}$ & 0.40 & 0.55 & 0.56 & 0.57 & 0.45 & 0.48 & 0.57 & 0.57 & 0.57 & 0.57 \\
\hline $\mathrm{W} / \mathrm{B}$ & 0.40 & 0.31 & 0.32 & 0.33 & 0.32 & 0.48 & 0.41 & 0.41 & 0.41 & 0.41 \\
\hline Compactness & 0.820 & 0.865 & 0.860 & 0.860 & 0.860 & 0.805 & 0.840 & 0.840 & 0.840 & 0.840 \\
\hline
\end{tabular}

${ }^{1}$ Effective water; ${ }^{2}$ absorption water.

To measure the consistency, the slump test was performed, according to EN 12350-2 [52], or the Vebe test, following EN 12350-3 [53] standard, and the degree of compactability test following EN 12350-4 [54], depending on whether the fresh mixture is plastic or dry, respectively. Along with consistency, in order to adjust the dosages of the constituents, the air content of the mixtures was also measured, according to EN 12350-7 [55] specification. The results of slump tests for MT mixtures resulted in values between 65 and $80 \mathrm{~mm}$, presenting no relevant differences, due to the admixture adjustment. Regarding the compactability test in BT mixtures, it resulted in values between 1.32 and 1.35; the results of Vebe test for the same mixtures ranged between 25 and $33 \mathrm{~s}$, corresponding the longer time to BTref mixture.

Figure 1 shows the tests to characterize the mechanical properties of the mixtures. The tests to access compressive strength were performed according to EN 12390-3 [56], on cubic specimens with $100 \mathrm{~mm}$ of edge, and the results were obtained using three specimens at each age (28 and 90 days). The splitting tensile strength was also characterized according to EN 12390-6 [57] at 28 and 90 days, using three prismatic specimens of $100 \times 100 \times 200 \mathrm{~mm}^{3}$ and the flexural strength was assessed following EN 12390-5 [58], in two prismatic specimens of $100 \times 100 \times 500 \mathrm{~mm}^{3}$. The Young's modulus test was performed at 28 days following the LNEC E 397 [59], using two prismatic specimens of $100 \times 100 \times 400 \mathrm{~mm}^{3}$. Figure 1 shows the tests performed to assess the durability of the mixtures. Capillary water absorption was evaluated in three specimens of $100 \times 100 \times 200 \mathrm{~mm}^{3}$, according to the LNEC E 393 [60]. The depth of water penetration under pressure was evaluated according to EN 12390-8 [61], using three cubic specimens with $150 \mathrm{~mm}$ edge for each mixture, after 28 days of water curing. The determination of carbonation resistance was assessed according LNEC E 391 [62], using two cylindrical samples with $100 \mathrm{~mm}$ diameter and $50 \mathrm{~mm}$ height, at each considered exposure period (56, 90 and 120 days). It was performed an accelerated laboratory test, exposed to an atmosphere of $5 \%$ carbon dioxide and $60 \%$ relative humidity. The chloride diffusion coefficient by non-steady state migration was tested according to LNEC E 463 [63], at 56 and 90 days, using three cylindrical specimens also with $100 \mathrm{~mm}$ diameter and $50 \mathrm{~mm}$ height, for each age. The surface electrical resistivity was evaluated on cylindrical specimens with $100 \mathrm{~mm}$ diameter and $200 \mathrm{~mm}$ height, at several ages, according to AASHTO T-358 [64]. 


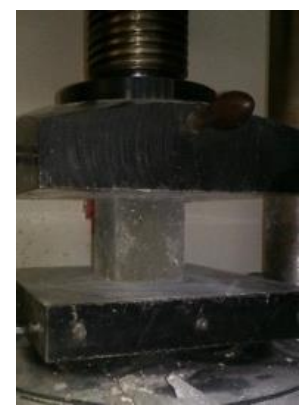

(a)

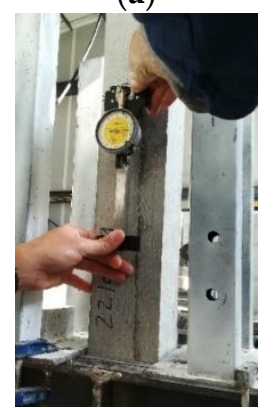

(d)

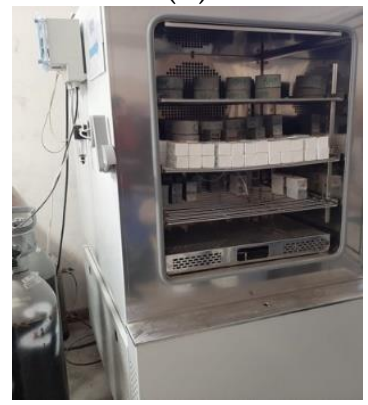

(g)

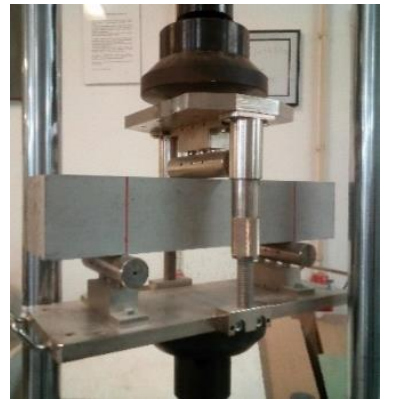

(b)

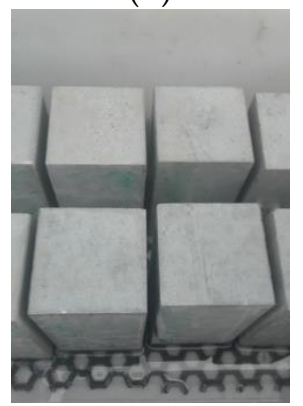

(e)

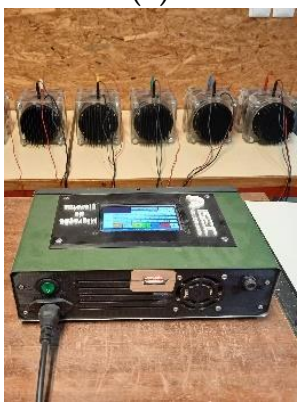

(h)

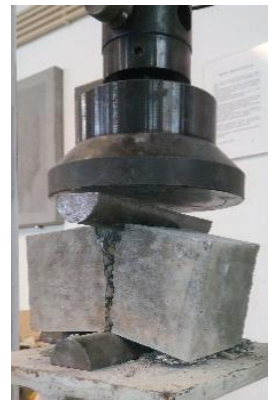

(c)

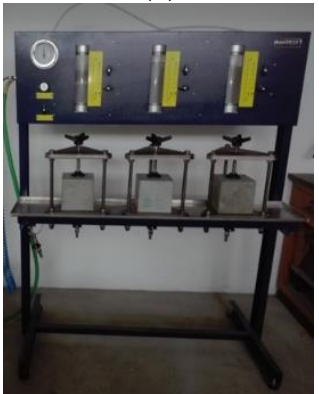

(f)

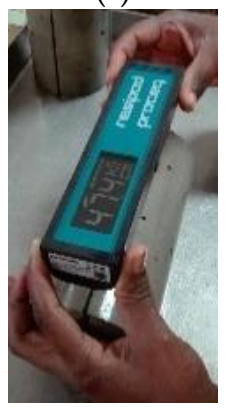

(i)

Figure 1. Tests to characterize the mechanical properties and durability: (a) compressive strength; (b) flexural strength; (c) tensile splitting strength; (d) Young's modulus; (e) capillary absorption; (f) water penetration under pressure; (g) carbonation resistance; (h) chloride ion diffusion by nonsteady state migration; (i) surface electrical resistivity.

\section{Results and Discussion}

\subsection{Mechanical Properties}

\subsubsection{Tensile Splitting Strength}

The results of average strengths of tensile splitting test, at 28 and 90 days, for BT and MT mixtures, are shown in Figure 2, as well as the error bars. In this test, only the final selected mixtures were characterized, since the binding matrix of the previous study was already characterized, and no significant variations were registered depending on the used additions [48]. In BT series, optimized mixtures with fly ash show lower strengths than the reference at 28 days, by $5 \%$ and $18 \%$, and at 90 days, by $7 \%$ and $16 \%$, respectively for mixtures BT200-FA and BT200-FA-RA. All the tensile splitting strengths at 90 days are higher than those at 28 days. These results were expected, since BTref has twice the amount of cement of the optimized mixtures. A slight decrease in the mixtures with the inclusion of recycled aggregates was noticed, when compared to mixtures with natural aggregates, due to their lower strength. In MT series, the optimized mixtures stand out for having strengths above the reference by $31 \%$ and 22\%, for MT250-FA and MT250-FA-RA, respectively, at 90 days, reflecting the effect of the increased compactness and of the addition of fly ash. 


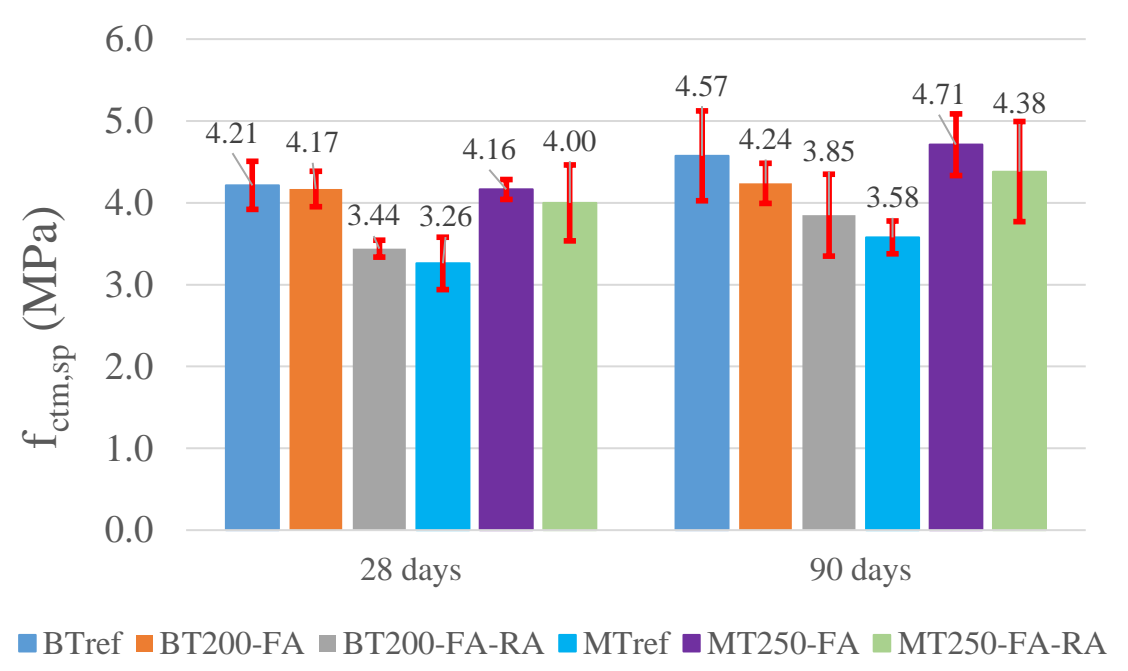

Figure 2. Tensile splitting strength for BT and MT mixtures, at 28 and 90 days.

The graph shown in Figure 3 shows the ratio between the tensile splitting strength test values and the codes' predicted values. The prediction of this strength followed the current design codes for all mixtures, EC2 [65] and MC10 [66], since the expressions of tensile splitting strength remains globally unaffected by recycled concrete aggregates incorporation [30]. The EC2 values, based on the compressive strength, confirm that the tested mixtures present consistent values with those predicted. The mixtures BT200FA, BT200-FA-RA and MTref have a tested value of about $10 \%$ lower than the predicted in EC2, which is not considered significant.

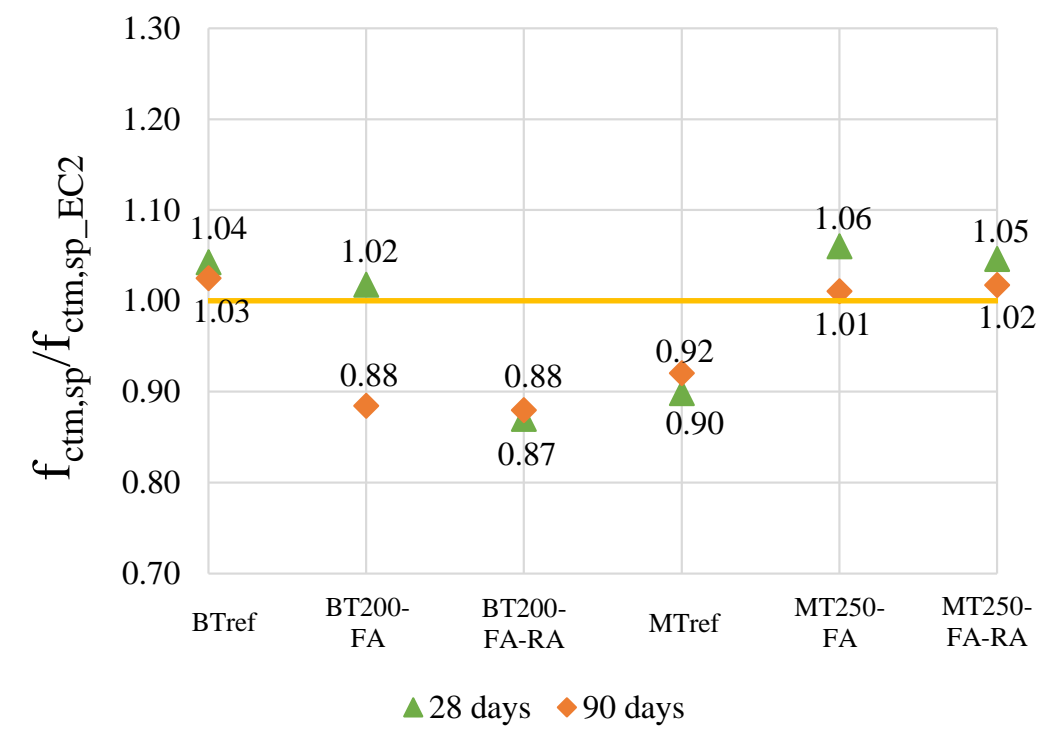

Figure 3. Ratio between tensile splitting strength tested values and those predicted in EC2.

\subsubsection{Flexural Strength}

Figure 4 shows graph plots with the flexural strengths, with the error bars, at 28 and 90 days, for the BT and MT series. The optimized mixtures have, in general, higher values than the references, with the exception of the pozzolans addition, which present values below the reference in $13 \%$ and $21 \%$, at 28 and 90 days, respectively, for BT, and similar values in MT series, compared to the reference. As mentioned, the opposite effect was found in mixtures with the additions of fly ash and slags. The first ones show increases of $3 \%$ and 20\%, namely for BT200-FA and MT250-FA, at 90 days; the latter present values $4 \%$ and 27\% higher than the references, for BT250-slag and MT250-slag, respectively, also at 
90 days. As the results also show, the flexural strength was not affected by the incorporation of $20 \%$ of RA, presenting similar values to those of mixtures with fly ash and natural aggregates, showing the same trend of results as those described in other studies $[67,68]$.

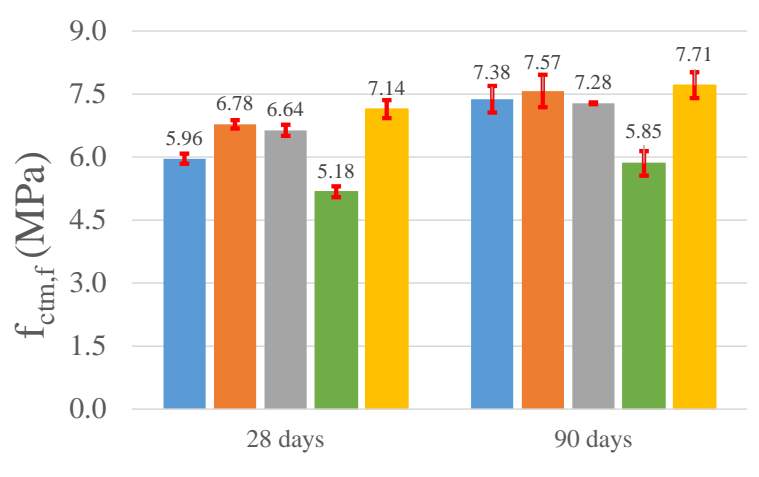

घTref $₫$ BT200-FA $₫$ BT200-FA-RA $₫$ BT200-Poz $₫$ BT250-Slag

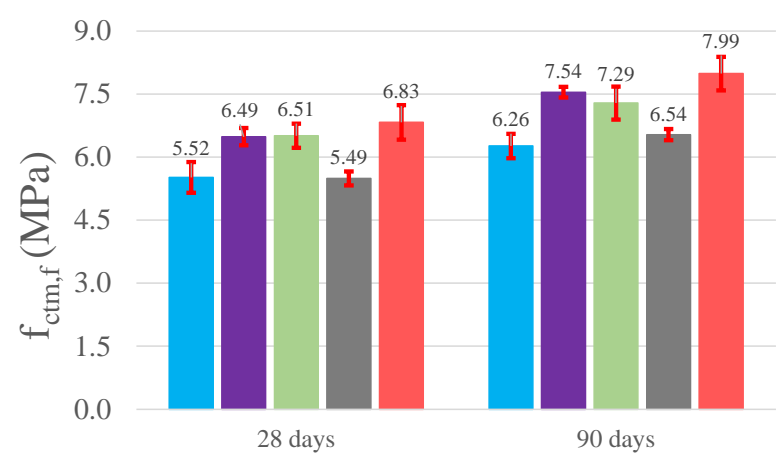

$\square$ MTref $\square$ MT250-FA $\square$ MT250-FA-RA $\square$ MT250-Poz $₫$ MT250-Slag

(b)

Figure 4. Flexural strength at 28 and 90 days: (a) BT mixtures; (b) MT mixtures.

According to EC2 [65], the tensile splitting strength results are usually lower than flexural, a trend also proved with this concrete mixtures. The prediction according to EC2 [65] and MC10 [66] of the tensile strength is directly related to the tensile splitting. Thus, and taking into account that the results of this test show reduced dispersion, it is possible to conclude that the tested values are in line with the codes prediction.

\subsubsection{Compressive Strength}

The compressive strength values with the error bars for the BT and MT mixtures, at 28 and 90 days, are shown in Figure 5. The addition of fly ash stands out, which, due to the pozzolanic effect, shows a notable evolution of strengths over time, with high values at 90 days, $10 \%$ and $26 \%$ higher than the references, for mixtures BT200-FA and MT250FA, respectively. This pozzolanic effect is less noticeable in mixtures with the addition of pozzolans, which have values very close to the references, both in BT and MT series. Mixtures with slag addition show similar results to the reference, in BT series, and, in MT, show slight improvements, circa $15 \%$ and $16 \%$, in relation to the reference, at 28 and 90 days, respectively. Regarding the results of the mixtures with RA, it is proved that the addition of recycled concrete aggregates decreases the compressive strength, when compared to the homonymous mixture with natural aggregates, despite presenting very similar results to the respective references, in BT series, and increases of 7\% and 14\% in MT250-FA-RA, at 28 and 90 days, respectively. As several studies concluded [30], considering the same (W/C) $)_{\text {eff }}$, the compressive strength of RAC is generally lower than the compressive strength of the same mixtures only with natural aggregates. However, this effect depends on the design and strength of the concrete matrix and also on the quality and strength of the concrete that origins the RA. In this study, considering that the concrete used to prepare the RA has 20\% lower strength that the designed concrete and that is mostly uncompact waste concrete, a strength lost was expected. The standard deviations of all mixtures are reduced, although with some exceptions, being, however, within the limits considered by EC 2 [65]. 


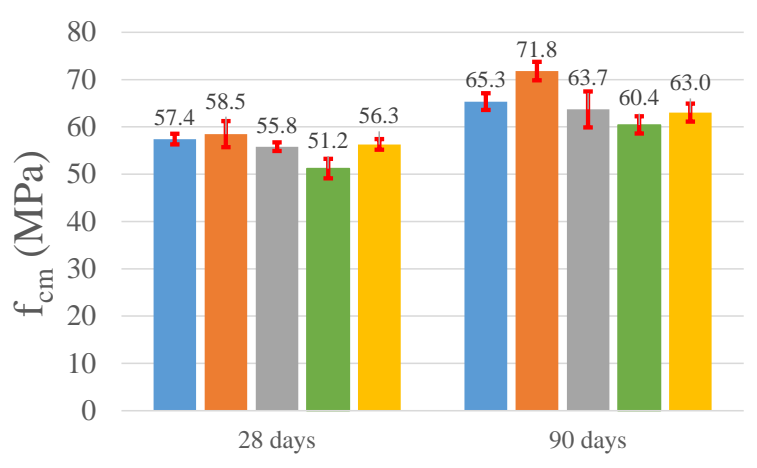

¿ BTref $₫$ BT200-FA $\approx$ BT200-FA-RA $\approx$ BT200-Poz $\approx$ BT250-Slag

(a)

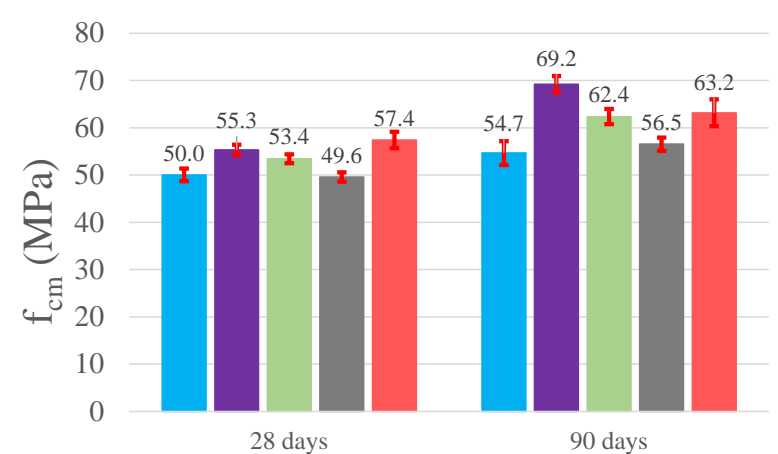

MTref $\square$ MT250-FA $\square$ MT250-FA-RA $\square$ MT250-Poz $\square$ MT250-Slag

(b)

Figure 5. Compressive strength at 28 and 90 days: (a) BT mixtures; (b) MT mixtures.

Figure 6 shows the evolution of compressive strength with age, of BT and MT mixtures, adjusted to the hardening curve of EC2 [65]. The hardening curve followed the expressions of current codes, since the inclusion of recycled aggregates does not have a significant influence on the prediction of compressive strength [30]. However, the inclusion of pozzolanic additions on the binder powder does influence the curve shape. For this reason, both series are divided into two graphs, changing the parameter " $\mathrm{s}$ " in the prediction expression for each: Figure $6 \mathrm{~b}, \mathrm{~d}$ show the results of mixtures containing pozzolanic additions (fly ash and pozzolans), adopting $s=0.38$, and the other presenting mixtures without pozzolanic additions, with $\mathrm{s}=0.20$.

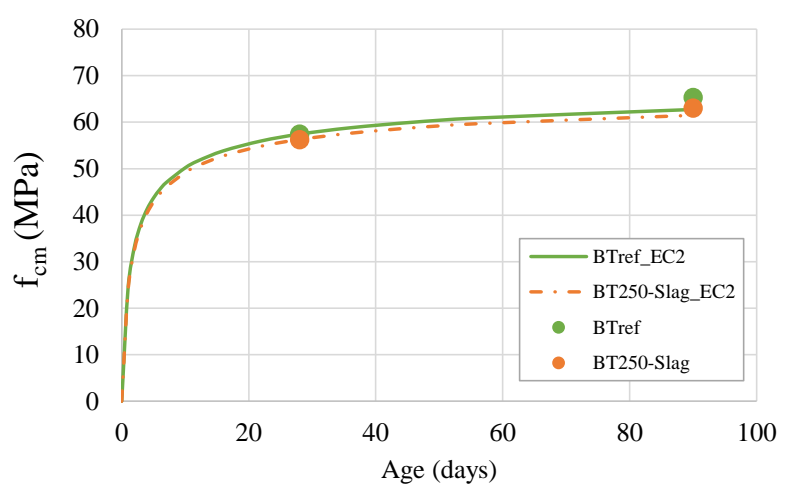

(a)

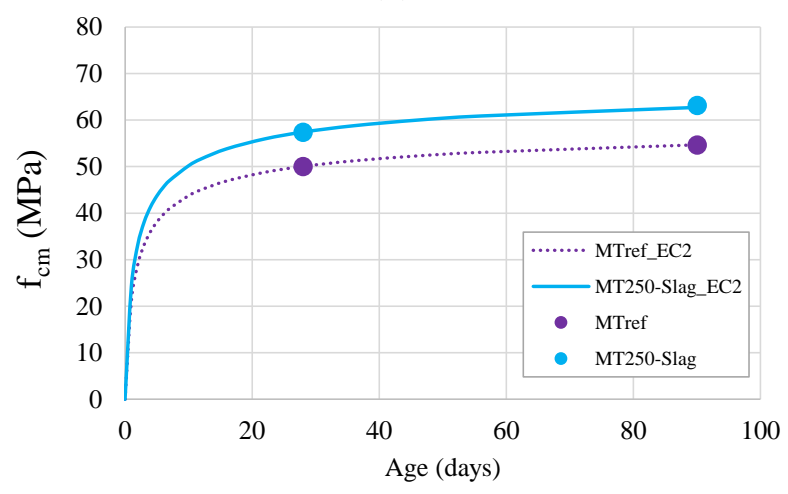

(c)

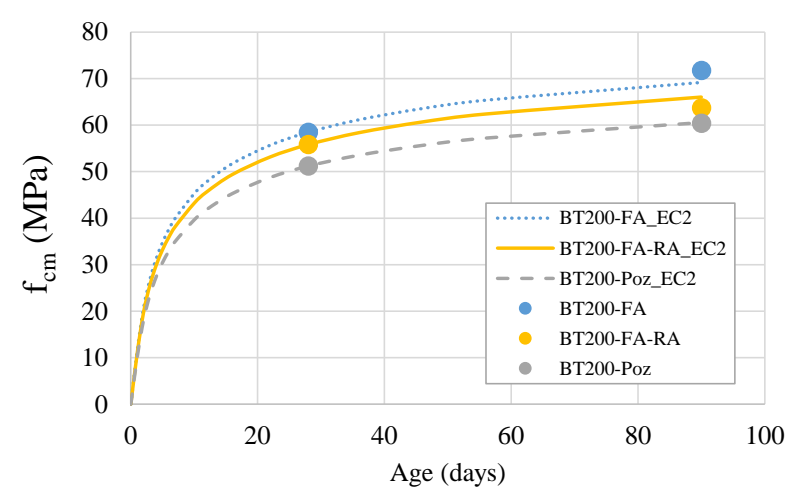

(b)

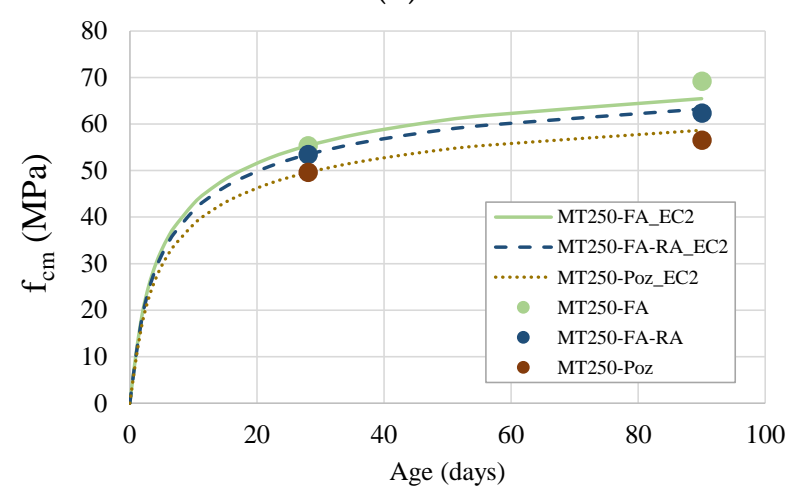

(d)

Figure 6. Evolution of average compressive strength with age and the influence of hardening in: (a) BT mixtures without pozzolanic addition; (b) BT mixtures with pozzolanic additions; (c) MT mixtures without pozzolanic additions; (d) MT mixtures with pozzolanic additions. 
By analyzing the graphs, it is possible to observe that, in both series, in mixtures without pozzolanic additions, the hardening curve is more pronounced at early ages and tends to stabilize earlier. On the contrary, the curves of mixtures with pozzolanic additions are less pronounced in early ages, developing more in later ages, being a clear consequence of the pozzolanic effect of the fly ash and pozzolans.

\subsubsection{Young's Modulus}

The measured average values of the Young's modulus at 28 days are shown in Figure 7. It is proved that the higher compactness, combined with the additions in cement replacement, is advantageous in increasing the Young's Modulus, comparatively to the references with plain cement. As expected, when recycled aggregates with lower strength are included, the values of Young's modulus decrease, as this recycled concrete aggregates have a lower stiffness and higher porosity than natural aggregates. The BT200-FA-RA and MT250FA-RA mixtures present values approximately $12 \%$ and $13 \%$ lower than the respective mixtures with the addition of fly ash and natural aggregates (BT200-FA and MT250-FA), being the reduction of $9 \%$ and $2 \%$ in relation to the respective references. In BT series, the addition of pozzolans stands out, with $11 \%$ increase compared to the reference. In MT series, this increase is also prominent, reaching 13\% above the reference, in MT250-Poz and MT250-FA mixtures.

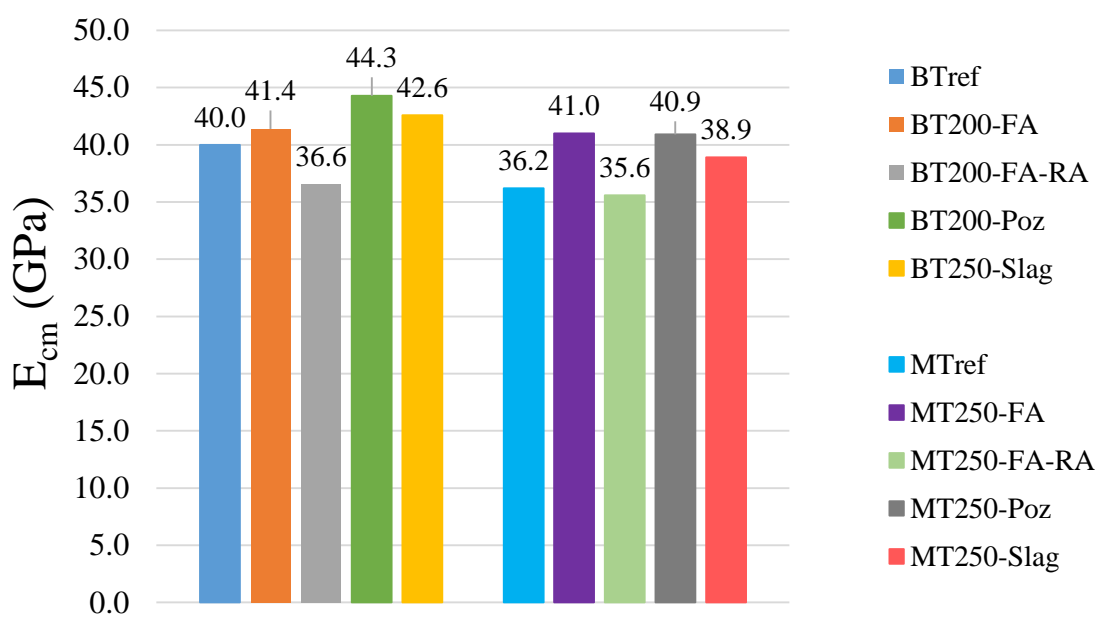

Figure 7. Young's modulus results for BT and MT mixtures, at 28 days.

Figure 8 presents the ratio between the results of tested Young's modulus and the predicted values of EC2 [65], calculated through Equation (1). However, recent research [30] proposes an adaptation of the expression to mixtures with the inclusion of recycled concrete aggregates, Equation (2):

$$
\begin{gathered}
\mathrm{E}_{\mathrm{cm}}=\mathrm{k}_{\mathrm{E}} \times \mathrm{f}_{\mathrm{cm}}{ }^{1 / 3} \\
\mathrm{E}_{\mathrm{cm} \_ \text {RAC }}=\mathrm{k}_{\mathrm{E}} \times\left(1-0.25 \times \alpha_{\mathrm{RA}}\right) \times \mathrm{f}_{\mathrm{cm}}{ }^{1 / 3}
\end{gathered}
$$

where $k_{E}$ is a factor that depends on the type of natural aggregates used in the mixtures, which is 9500 for siliceous aggregates; $f_{c m}$ is the average compressive strength; $\alpha_{R A}$ is the substitution rate of normal by recycled concrete aggregates and is given by the ratio between the quantity of recycled sand and gravel and the total quantity of aggregates in the concrete.

The analysis of the graph allows to conclude that the values obtained in the Young's modulus test are always higher than the predicted. Mixtures with the addition of pozzolans stand out, with values $26 \%$ and $17 \%$ higher than those predicted, in the BT200-Poz and MT250-Poz mixtures, respectively. 


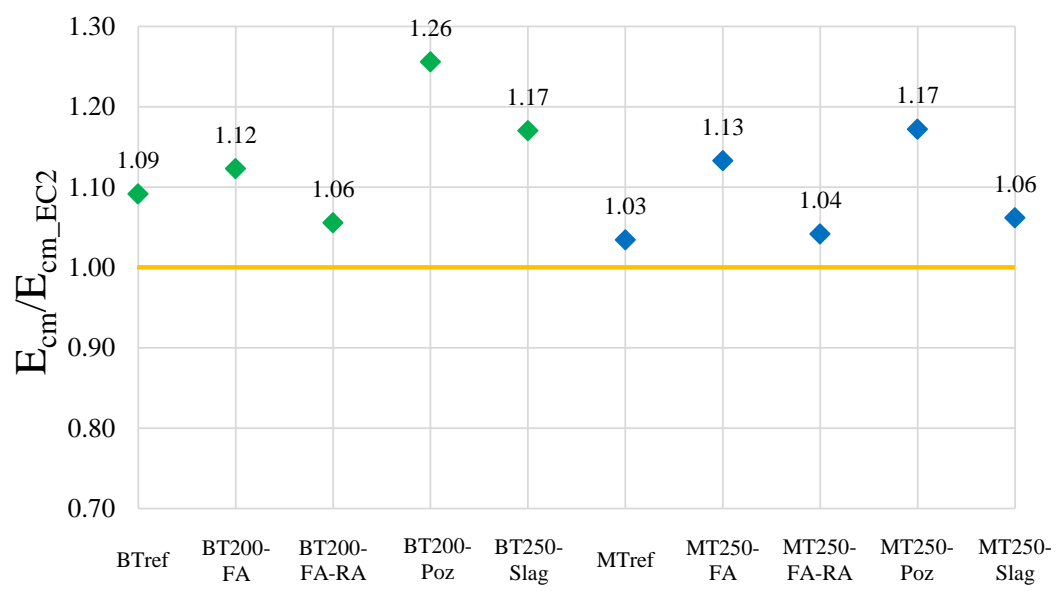

Figure 8. Ratio between Young's modulus tested values and those predicted in EC2.

\subsection{Durability}

\subsubsection{Water Absorption through Capillarity}

The characterization of all mixtures had already been carried out in mortar matrices [48], which is why not all the results are presented, but only the final selected mixtures with fly ash addition. The results revealed that mixtures with higher packing density, both BT and MT, and combined with slag addition, presented the best results, absorbing down to $60 \%$ less water. Fly ash and pozzolan addition also revealed good performance in reducing water absorption.

Figure 9 shows the evolution of capillary absorption values, $S_{a}\left(\mathrm{mg} / \mathrm{mm}^{2}\right)$ with the square root of time, for BT and MT mixtures, after 28 days curing. By analyzing the results, performed on three consecutive days, it can be concluded that the capillary water absorption occurs with more intensity in the first hours and tends to stabilize over time, presenting a nonlinear evolution. In both series, the decrease of the powder content combined with the increase of compactness and the partial replacement of cement by additions proved to be advantageous in decreasing water absorption over time. However, this fact is more prominent in MT series, since the values of optimized mixtures in BT series remain similar to the reference. In the latter, the addition of fly ash (50\% of replacement rate) and the inclusion of $20 \%$ of recycled aggregates does not change the capillary absorption of concrete. Comparing the two series, it is noticeable that the amount of cement influences this parameter, proved by the lower values of the BTref (with cement content of $400 \mathrm{~kg} / \mathrm{m}^{3}$ ), in relation to MTref (with $400 \mathrm{~kg} / \mathrm{m}^{3}$ ). However, the optimized mixtures with fly ash show that the increase in compactness and the replacement of cement by this addition also has a great influence on the reduction of capillarity, as the concrete matrix becomes more compact and less permeable. In BT series, despite of the $50 \%$ of cement replacement, the capillary absorption is similar to reference. However, in MT mixtures, the optimized matrix with high compactness, and about $30 \%$ of cement replacement by fly ash, promotes a significant reduction in capillarity, of at least 35\%.

In MT mixtures, the partial cement replacement by fly ash and $20 \%$ of recycled concrete aggregates, mixture MT250-FA-RA, leads to down to $44 \%$ less water absorption, and the mixture with natural aggregates (MT250-FA) presents equally reduced values. Figure 10 shows the quality of the concrete as a function of the capillary absorption coefficient, $\mathrm{S}_{\mathrm{a}}$. Browne [69] proposed the following classification for the quality of the concrete, as a function of the $S_{a}$ coefficient: above $0.2 \mathrm{mg} / \mathrm{mm}^{2} \times \mathrm{min}^{1 / 2}$ is "low quality"; between 0.1 and $0.2 \mathrm{mg} / \mathrm{mm}^{2} \times \mathrm{min}^{1 / 2}$ is "medium quality" and below $0.1 \mathrm{mg} / \mathrm{mm}^{2} \times \mathrm{min}^{1 / 2}$ is "high quality". According to this classification, all mixtures are considered to be of "high quality", regarding the water absorption through capillarity. In addition, due to pozzolanic effect of the optimized mixtures, there is great potential to improve the performance for longer ages, beyond 28 days. 


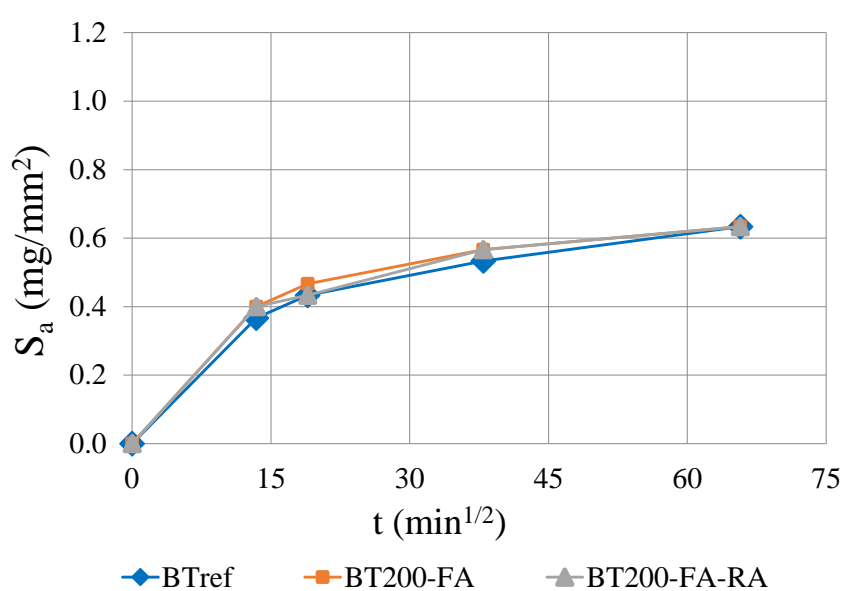

(a)

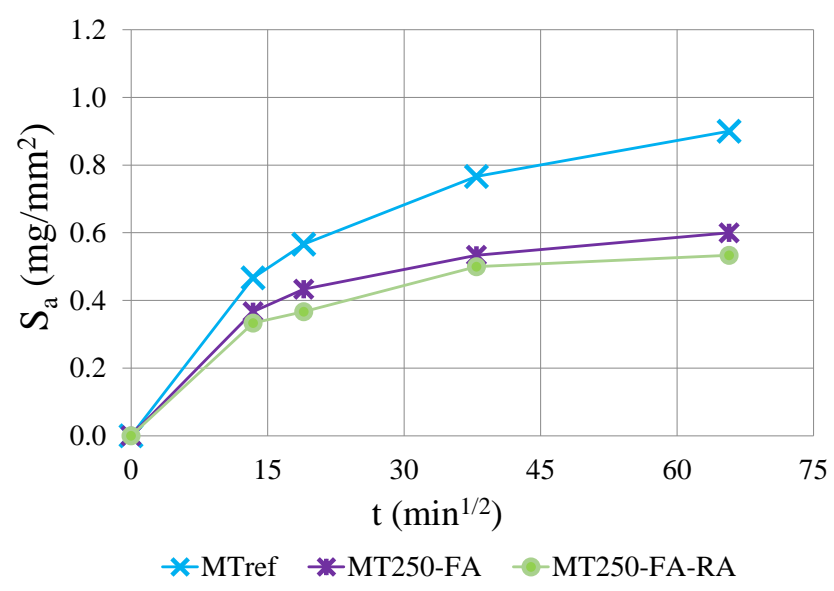

(b)

Figure 9. Capillarity water absorption through square root of time: (a) BT mixtures; (b) MT mixtures.

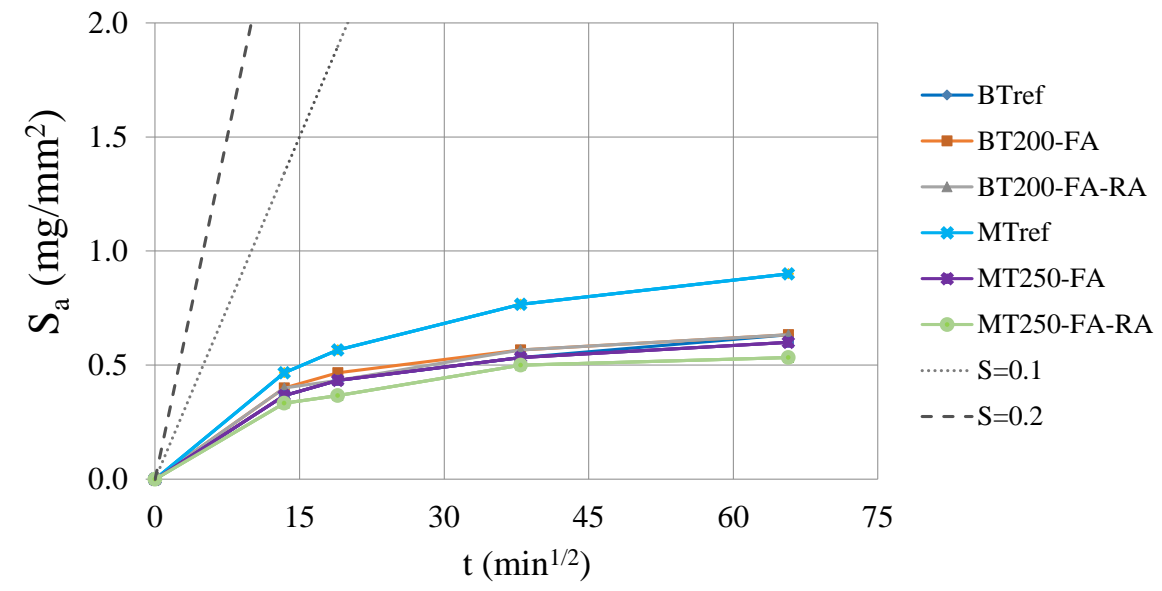

Figure 10. Capillary water absorption through square root of time.

\subsubsection{Water Penetration Depth under Pressure}

Figure 11 shows the water penetration depth under pressure of MT mixtures, at 28 days. This test was not performed on BT mixtures, since the molded faces have high porosity, which would make the necessary sealing quite difficult.

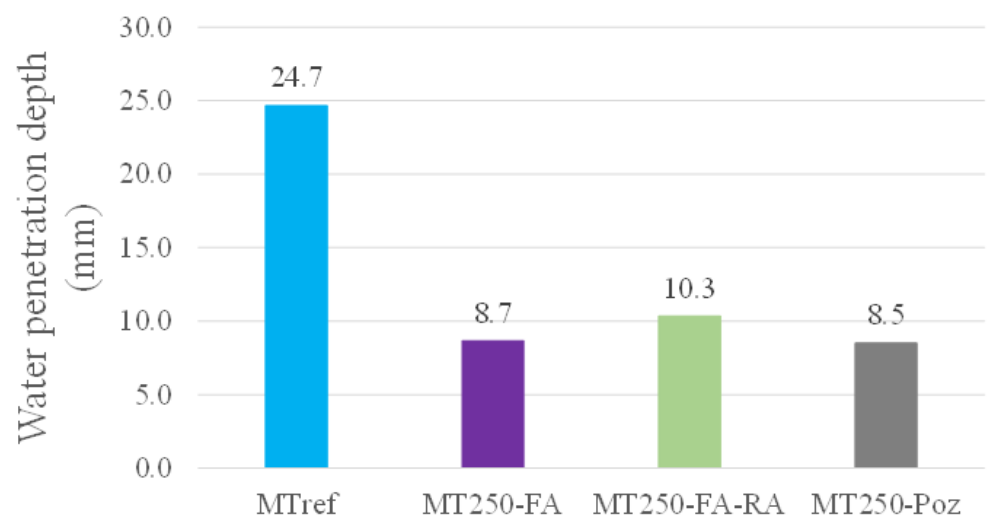

Figure 11. Water penetration depth under pressure for MT mixtures, at 28 days.

Similar to what occurs with the absorption of water by capillarity, the addition of fly ash shows significant reductions of water penetration under pressure. The optimized 
mixture with higher compactness and addition of fly ash, MT250-FA, presents values down to $65 \%$ of less penetration depth when compared to the reference. The substitution of $20 \%$ natural aggregates through recycled concrete aggregates, combined with the previous matrix, make its compact matrix noteworthy, showing a 58\% reduction in relation to the reference. The mixture with the addition of pozzolans, MT250-Poz, reveals the lowest water penetration result, very close to the value of the mixture with fly ash addition. This analysis reinforces that the higher compactness, and matrix refinement due to fly ash addition, of the optimized mixtures, it is quite important to reduced concrete permeability. In addition, the pozzolanic effect will promote even better results at more advanced ages, where lower penetration results are potentially expected.

\subsubsection{Carbonation Resistance}

The phenomenon of concrete carbonation is mainly associated with the penetration, by diffusion, of carbon dioxide. The decrease in $\mathrm{pH}$ is visible through the reaction with phenolphthalein sprayed in concrete, in which the carbonated area is colorless (Figure 12).

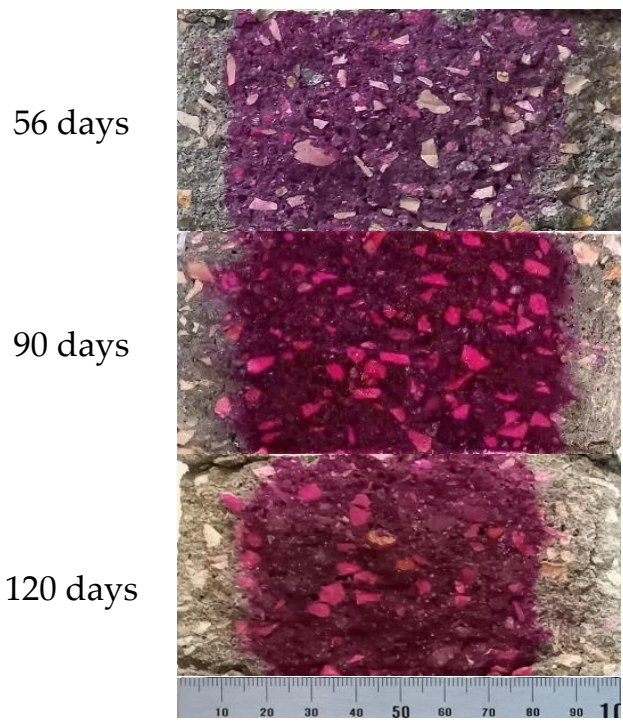

(a)

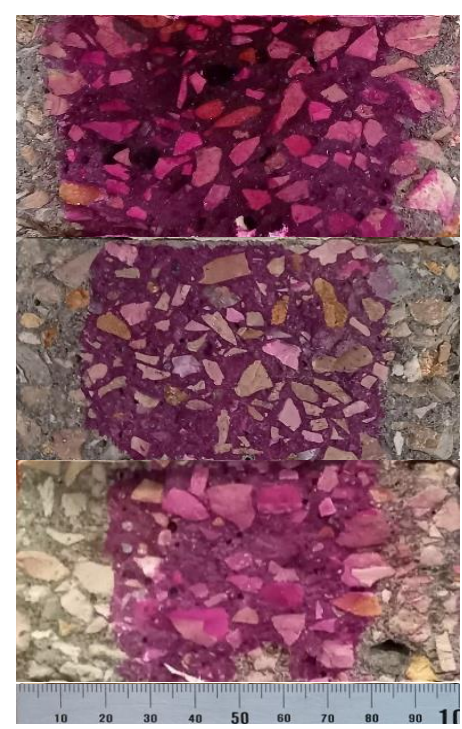

(b)

Figure 12. Specimens tested regarding resistance to carbonation over exposure time: (a) BT200-FARA; (b) MT250-slag.

Figure 13 shows the results evolution of the carbonation depth $\left(\mathrm{C}_{\mathrm{di}}\right)$, measured in $\mathrm{mm}$, of the BT and MT series, with the square root of time. The analysis of carbonation depth, $C_{\text {depth}}$, of the studied mixtures proved to evaluate that it varies with the square root of time, as expected, with a general trend to be linear. The amount of cement highly influences this parameter, and that effect is more evident in BT mixtures, whose reference contains a higher amount of cement than in MT mixture. However, BT250-slag mixture proves that the slags are the most beneficial additions in this series, showing a slower initial evolution and only $46 \%$ of increased carbonation depth in relation to the reference. On the contrary, also in BT series, the increased compactness and the partial replacement of cement by fly ash (BT200-FA and BT200-FA-RA) is not able to avoid the increase of the carbonation depth, up to $122 \%$, when compared to the reference. Through these mixtures, it can also be concluded that the inclusion of $20 \%$ of recycled aggregates does not increase carbonation, on the contrary, it is slightly lower. Previously to this study, in mortar matrices, pozzolans additions did not reveal promising results in preventing carbonation [48]. In concrete mixtures, the results proved to follow the same trend. 


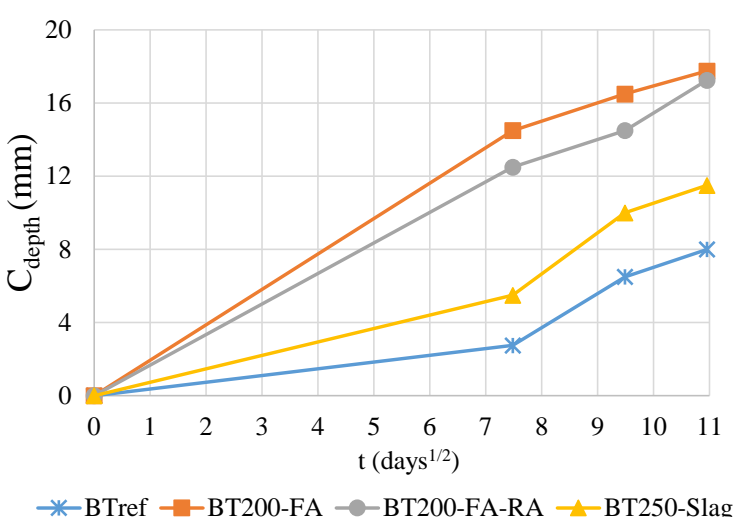

(a)

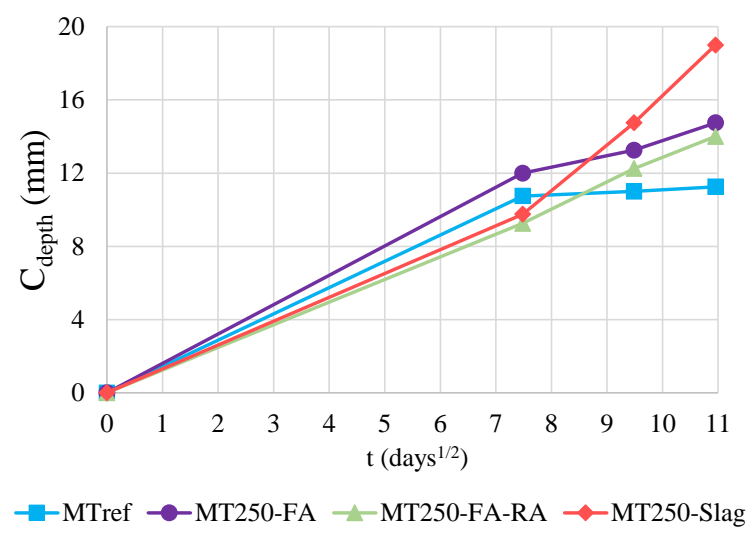

(b)

Figure 13. Carbonation depth through square root of time: (a) BT mixtures; (b) MT mixtures.

In the MT series, the difference between the optimized mixtures and the reference is not so evident, since the cement replacement is lower $(30 \%)$, presenting a similar evolution of the carbonation depth for the first testing ages. This evolution is less pronounced after 56 days, with the exception of the MT250-slag mixture, which shows a more pronounced increase of the carbonation depth, presenting values up to $69 \%$ above reference. This effect was not noticed for younger testing ages on the preliminary study of mortar matrices, since the carbonation evolved linearly with square root of time up to 90 days. Unlike the BT series, the optimized mixtures with fly ash of MT series, MT250-FA, present values closer to the reference, showing an increase of up to $31 \%$, at the longer tested age. The inclusion of recycled aggregates, once again, did not harm the performance of the concrete at this parameter, presenting similar evolution with lower values to the homonymous mixture with natural aggregates. Despite additional absorption, water is considered in concrete with RA, the probable absorption during setting time may reduce the effective water of the mixtures with RA, which seems to result on a positive effect on carbonation reduction.

\subsubsection{Chloride Migration}

The penetration depth of chlorides into the specimen is visible through the silver colour area, which corresponds to the silver nitrate precipitation, as is shown in Figure 14.

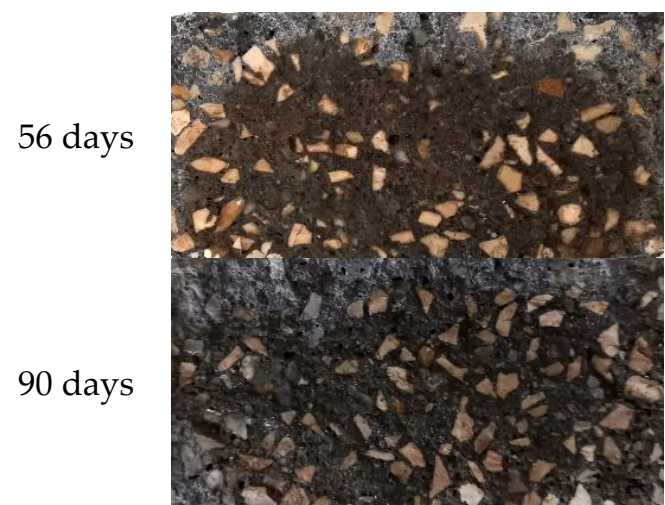

(a)

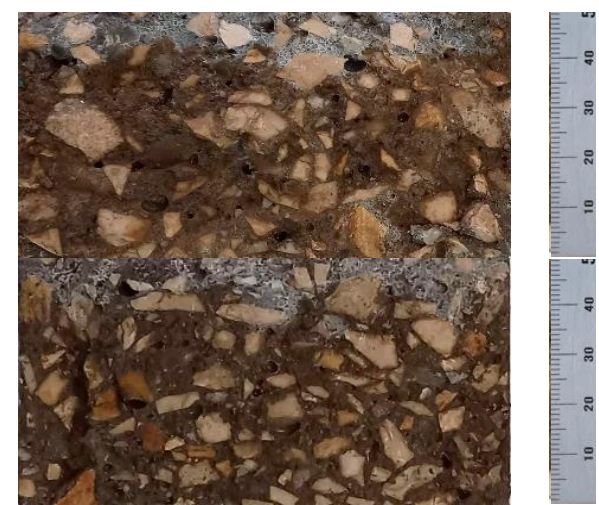

(b)

Figure 14. Specimens tested for resistance to chloride migration, at 56 and 90 days: (a) BT200-FA; (b) MT250-Poz.

The results shown in Figure 15 represent the chloride diffusion coefficient $\left(D_{0}\right)$ by non-steady state migration test at 56 and 90 days. In this test, the lower the $\mathrm{D}_{0}$ coefficient, the higher the resistance to chloride migration, the durability performance also being higher. This test highlights the benefit of pozzolanic additions (both fly ash and pozzolans), 
bringing the pozzolanic refinement to the porous network of the matrix, combined with increased compactness, in reducing the chloride migration.

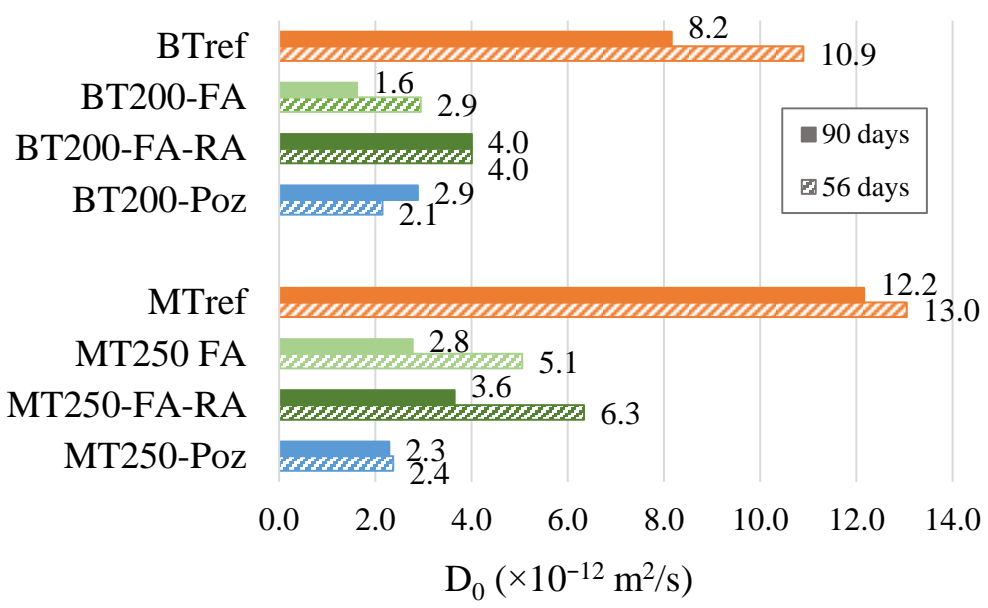

Figure 15. Chloride diffusion coefficient $\left(\mathrm{D}_{0}\right)$, at 56 and 90 days, for BT and MT mixtures.

The addition of natural pozzolans stands out positively by presenting very low $\mathrm{D}$ values, down to $64 \%$ and $81 \%$, below the references for mixtures BT200-Poz and MT250-Poz, respectively, at 90 days. Due to its high content of alumina, when pozzolans are combined with cement, it promotes a reduction of the porous structure of the matrix with time, being beneficial to durability related with to corrosion risk, induced by chloride penetration, and to strength performance.

The results reveal similarly low values for the BT200-FA and MT250-FA mixtures, down to $80 \%$ and $77 \%$, respectively, at 90 days, when compared to the references. This effect is already scientifically known. However, the inclusion of recycled aggregates affects the increase in the diffusion coefficient, when compared with similar mixtures with only natural aggregates, although it presents values $51 \%$ and $70 \%$ below the references for BT200-FA-RA and MT250-FA-RA, respectively. It is important to note that, in the BT200FA-RA mixture, the $\mathrm{D}_{0}$ coefficient maintain its value from 56 to 90 days. Contrarily, the MT250-FA-RA mixture reduces the diffusion coefficient. Apparently, the higher cement content and lower replacement rate, in comparison to BT mixtures, is the probable reason for that difference.

Figure 16 show the classification of the chloride penetration resistance of concrete as a function of the chloride diffusion coefficient, $\mathrm{D}_{0}$, as used in [33].

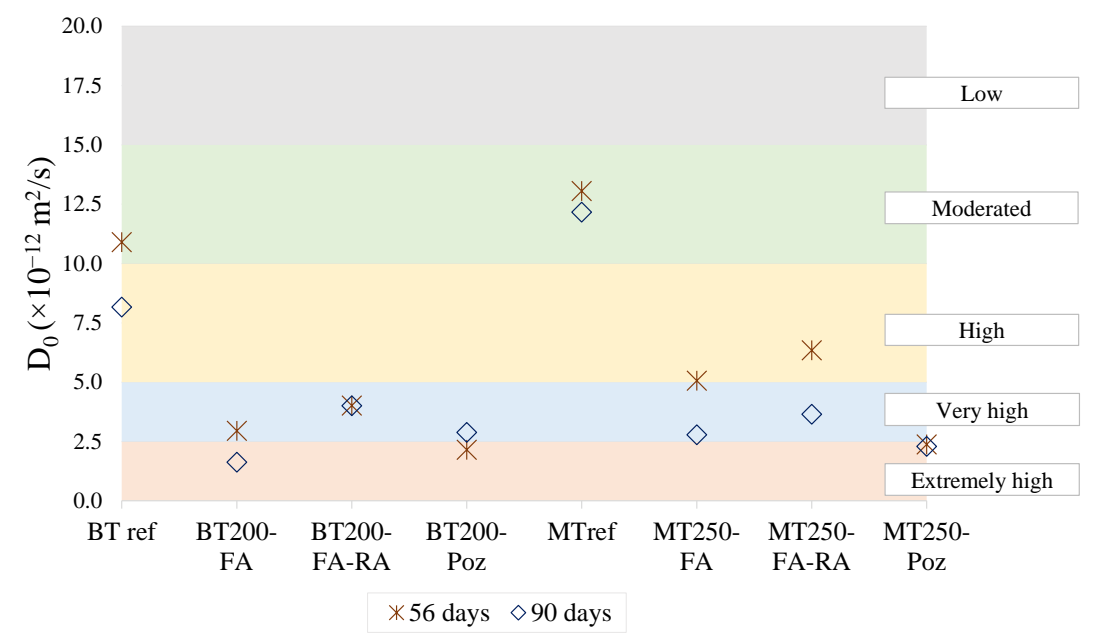

Figure 16. Chloride penetration resistance of concrete depending on the chloride diffusion coefficient $\left(\mathrm{D}_{0}\right)$. 
According to this classification, and by analyzing the plotted graph, it is possible to note that only the references, both BT and MT, present a "moderate" resistance of concrete to chloride penetration, although the BTref mixture achieves a classification of "high" resistance, at 90 days. Mixtures optimized with additions and increased compactness reveal very promising classification results. The mixtures with the addition of pozzolans (more evident in MT250-Poz) stand out for mostly obtaining the classification of "extremely high" resistance to chloride penetration. Mixtures with fly ash also stand out for the same reason, although they are mostly classified as "very high" resistance. The replacement of natural aggregates by recycled concrete aggregates does not greatly harm the mixtures, since, after 90 days, they are maintained, at least, with the classification of "very high" resistance.

\subsubsection{Concrete Surface Resistivity}

Figure 17 shows the results of the surface electrical resistivity of concrete $(\rho)$, of the BT and MT mixtures, over time. This is a fast test allowing to indirectly predict the permeability to fluids and the diffusion of chloride ions in concrete. The presented results were determined in mortar matrixes of the same concrete formulations, since they show the same trend as in concrete.
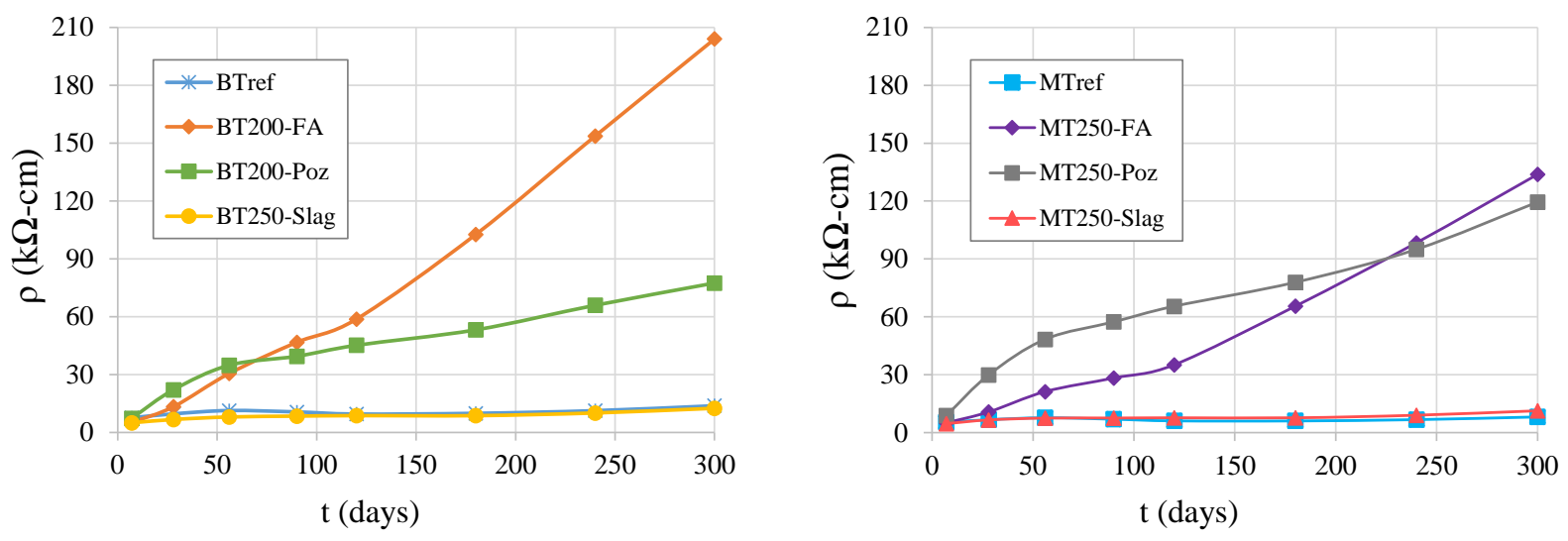

Figure 17. Concrete surface resistivity over time: BT mixtures (left); MT mixtures (right).

Through the analysis of the graphs, in both series, it is possible to conclude that the slag addition does not lead to positive results in this test, presenting similar values to the references with plain cement binder. The reference mixtures and those with slag addition have no significant variations of electrical resistivity with age. The opposite is found in mixtures with pozzolanic additions, which present results that increase with the testing age. Mixtures with fly ash addition stand out for having higher values, almost 20 times higher than the references, for both BT200-FA and MT250-FA mixtures, measured at 450 days. The pozzolan addition shows resistivity values nearly 6 and 16 times higher than the references, for BT250-Poz and MT250-Poz, respectively, also at 450 days. Despite fly ash and natural pozzolan both being pozzolanic additions, their influence on resistivity is different with time regarding the evolution and the optimal replacement rate. The electrical resistivity evolves faster with age, up to 56 days, for mixtures with pozzolan addition and develops a smoother evolution after that. Contrarily, the mixtures with fly ash addition present smooth evolution at younger ages, but after 120 days the increase in rate with age tends to be faster, probably due to higher pozzolanic reactivity at greater ages. However, at 300 days, mixtures with both additions tend to stabilize, although mixtures with fly ash stabilize more smoothly. In the MT series, the MT250-Poz mixture is very close to MT250FA, showing closer values of resistivity evolution over time; a lower cement replacement by pozzolans, in comparison to the BT series, seems to suggest a possible optimal for moderate replacement rates (circa 30\%). Contrarily, in the BT series, the higher cement replacement of fly ash in the mixture BT200-FA, 50\%, suggest that the resistivity increase is more effective for higher fly ash content, mainly for longer ages. In fact, in a previous study 
carried out in mortar matrixes [48], it was possible to draw this conclusion, corroborated also by Kurda et al. [70]. The optimal proportions, for both types of pozzolanic additions, regarding the increase in electrical resistivity and the reduction of chloride migration need to be studied in future research. Further, due to its known relation to the resistance to chloride migration, and as is evident from the analysis of the graphs, the pozzolanic effect promotes an improved behavior at older ages. That effect increases the refinement of the internal porous microstructure with age, both for pozzolan and for fly ash; however, at different rates, the fly ash being lower at shorter ages, but with a greater effect in longer ages, and mainly when high replacement rates are used.

The followed standard [64] refers to a correlation between the resistivity test and the chloride ion penetration, establishing limit parameters. At 450 days of age, the mixtures with additions of pozzolan and fly ash of the BT and MT series were classified, regarding the penetration of chloride ion, as being "very low", with $\rho$ values between 37 and $254 \mathrm{k} \Omega-\mathrm{cm}$. For the reference mixtures, at the same age, BTref was classified as "moderate" $(12 \mathrm{k} \Omega-\mathrm{cm}<\rho<21 \mathrm{k} \Omega-\mathrm{cm})$ and MTref as "high" $(\rho<12 \mathrm{k} \Omega-\mathrm{cm})$. Mixtures with slag additions were classified as "high", which is why concrete mixtures with that addition are not recommended for exposure to chlorides.

Figure 18 proves the high correlation between the chloride diffusion coefficient, $\mathrm{D}_{0}$, of the mixtures and the surface resistivity, $\rho$, of the corresponding matrixes, which is very reliable, and was proved by the high $\mathrm{R}^{2}$ values of the power function.

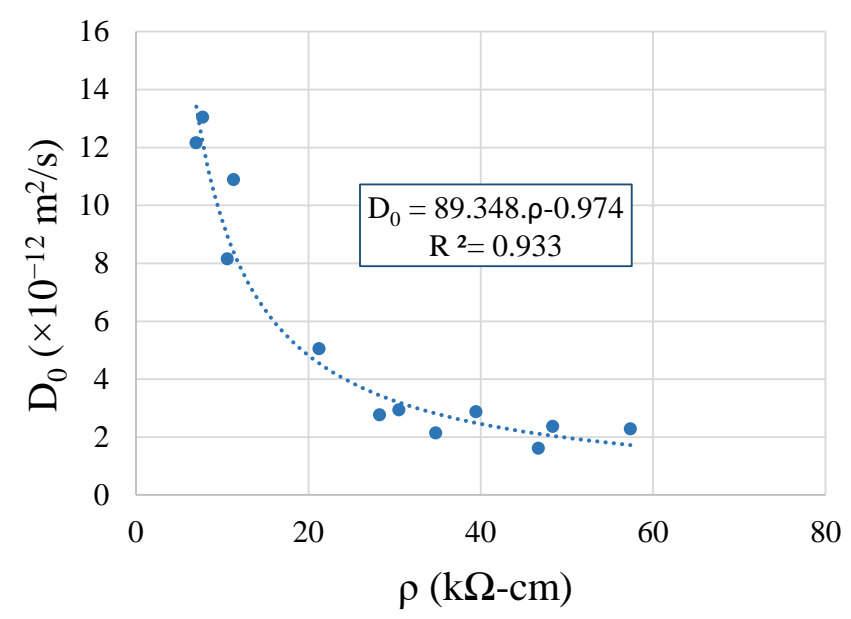

Figure 18. Correlation between the chloride diffusion coefficient and the surface resistivity.

\subsubsection{Prediction of Service Life}

- Environmental exposure XC (corrosion induced by carbonation)

The determination of carbonation resistance, $\mathrm{R}_{\mathrm{C} 65}\left(\mathrm{~kg} \times\right.$ year $\left./ \mathrm{m}^{5}\right)$, of each developed concrete was calculated using Equation (3) and the carbonation depth, $\mathrm{C}_{\mathrm{di}}$. These values were measured after the concrete was exposed for a certain time to a highly concentrated carbon dioxide environment, $\mathrm{C}_{\text {acel }}, 90 \times 10^{-3} \mathrm{~kg} / \mathrm{m}^{3}$.

$$
\mathrm{R}_{\mathrm{C} 65}=\frac{2 \cdot \mathrm{C}_{\mathrm{acel}} \cdot \mathrm{t}_{\mathrm{i}}}{\mathrm{X}_{\mathrm{i}}^{2}}
$$

where $t_{i}$ is the time of exposure in years, and $X_{i}$ has the same meaning as $C_{d i}$ (carbonation depth). Table 3 presents the average values of carbonation resistance, $R_{C 65}$, at 56,90 , and 120 days to minimize the errors related with the measurement of the carbonation depth. 
Table 3. Average values of carbonation resistance, $\mathrm{R}_{\mathrm{C} 65}$.

\begin{tabular}{cc}
\hline Concrete & $\mathbf{R}_{\mathbf{C 6 5}}\left(\mathbf{k g} \cdot \mathbf{y e a r} / \mathbf{m}^{\mathbf{5}}\right)$ \\
\hline BTref & 1875.6 \\
BT200-FA & 160.7 \\
BT200-FA-RA & 195.6 \\
BT250-Slag & 601.4 \\
MTref & 357.8 \\
MT250-FA & 238.9 \\
MT250-FA-RA & 306.8 \\
MT250-Slag & 219.5 \\
\hline
\end{tabular}

The deterioration of reinforced concrete due to steel corrosion can be divided into two periods: the initiation, $t_{\mathrm{ic}}$, and the propagation of corrosion, $\mathrm{t}_{\mathrm{p}}$. The minimum propagation period, $t_{p}$, depends of several factors, such as the exposure class.

Table 4 presents the propagation period, $\mathrm{t}_{\mathrm{p}}$, according to LNEC E-465 [71]. Thus, considering that the intended service life, $\mathrm{t}_{\mathrm{g}}$, is equal to 50 years, and considering that the electrical poles can be associated to the reliability class (RC1), where the safety factor of the service life is equal to 2.0 [71], the design period of initiation, $\mathrm{t}_{\mathrm{i} c}$, can be determined using Equation (4) (Table 4).

$$
t_{\text {ic }}=\gamma\left(t_{g}-t_{p}\right)
$$

Table 4. Values of $t_{p}$ and $t_{i c}$ for each exposure class, $\mathrm{XC}$.

\begin{tabular}{ccccc}
\hline $\begin{array}{c}\text { Periods during } \\
\text { Service Life }\end{array}$ & XC2 & XC3 & XC4 (Dry Reg.) & XC4 (Wet Reg.) \\
\hline$t_{\mathrm{p}}$ (years) & 10 & 45 & 15 & 5 \\
$\mathrm{t}_{\mathrm{ic}}$ (years) & 80 & 10 & 70 & 90 \\
\hline
\end{tabular}

The minimum concrete cover required to guarantee the resistance against the reinforcement corrosion due to carbonation, $\mathrm{c}_{\mathrm{min} \text {,dur, }}$ is determined using Equation (5), considering the $\mathrm{R}_{\mathrm{C} 65}$ already calculated for each concrete and $t$ is equal to the design period of initiation, $t_{i c}$ (Tables 4 and 5).

$$
X=\sqrt{\frac{2 \times 0.0007 \times \mathrm{t}_{\mathrm{ic}}}{\mathrm{R}_{\mathrm{C} 65}}} \times \sqrt{\mathrm{k}_{0} \times \mathrm{k}_{1} \times \mathrm{k}_{2}} \times\left(\frac{\mathrm{t}_{0}}{\mathrm{t}_{\mathrm{ic}}}\right)^{\mathrm{n}}
$$

Table 5. Minimum cover, $c_{m i n, d u r}$, to resist corrosion induced by carbonation in electrical concrete poles.

\begin{tabular}{ccccc}
\hline \multirow{2}{*}{ Concrete } & \multicolumn{4}{c}{ Minimum Cover, $\mathbf{c}_{\text {min, dur }}$ (mm) } \\
\cline { 2 - 5 } & XC2 & XC3 & XC4 (Dry Reg.) & XC4 (Wet Reg.) \\
\hline BTref & 3 & 4 & 5 & 6 \\
BT200-FA & 9 & 14 & 19 & 21 \\
BT200-FA-RA & 8 & 12 & 17 & 19 \\
BT250-Slag & 5 & 7 & 10 & 11 \\
MTref & 6 & 9 & 12 & 14 \\
MT250-FA & 8 & 11 & 15 & 17 \\
MT250-FA-RA & 8 & 12 & 16 & 90 \\
MT250-Slag & 80 & 10 & 70 & \\
\hline
\end{tabular}

The meanings of the symbols are: $k_{0}$ is a factor related with test conditions and is equal to $3, \mathrm{k}_{1}$ is a factor related with relative humidity, $\mathrm{k}_{2}$ is a factor related with concrete cure conditions and is also $1, \mathrm{n}$ is a factor related with the influence of wetting/drying cycles over time, and $t_{0}$ is the reference period and is 1 year.

The Equation (5) can also be used to predict the service life, $t_{g}$, when the cover used is already predefined. For this purpose, $\mathrm{X}$ must be equal to the cover predefined, and $t_{\text {ic }}$ 
is the unknown variable that should be calculated using the Equation (5). Usually, the randomness of the factors that affect the service life happens during the initiation period, so after the determination of $t_{i c}$, the service life, $t_{\mathrm{g}}$, is calculated adding to this value the propagation period, $t_{\mathrm{p}}$, presented in Table 4 .

The service life was computed for different exposure classes considering covers equal to 15,20 , and $30 \mathrm{~mm}$, see Figure 19 and Table 6 . The presented covers only concern durability and were not determined to ensure proper fire resistance nor adequate transmission of bond forces between rebars and concrete. For the standard for concrete poles, the minimum cover is related to the exposure conditions and also to the concrete strength; parameters of composition were not considered.

Table 6. Prediction of the service life, tg, for different cover values (years), classes XC.

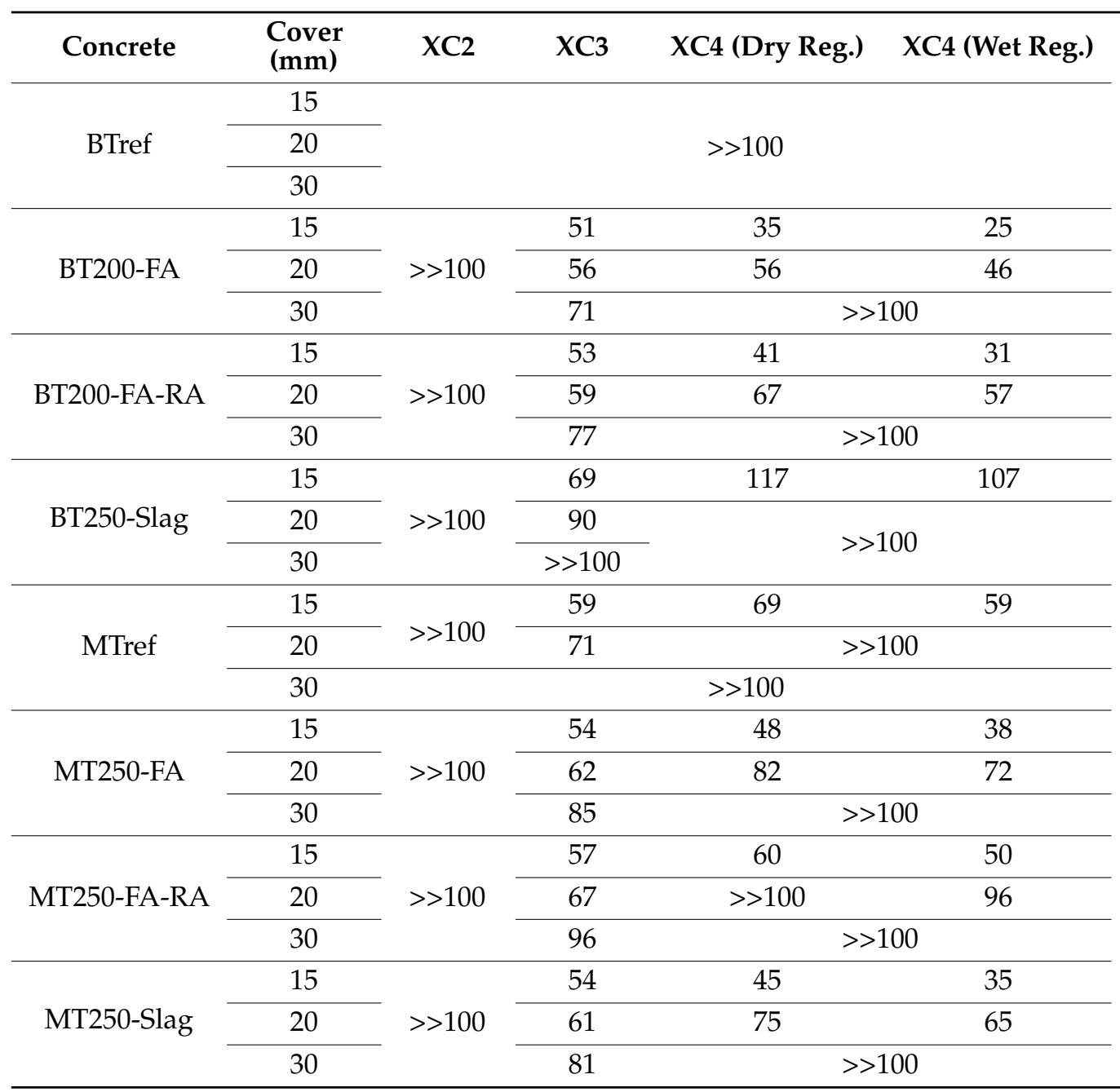




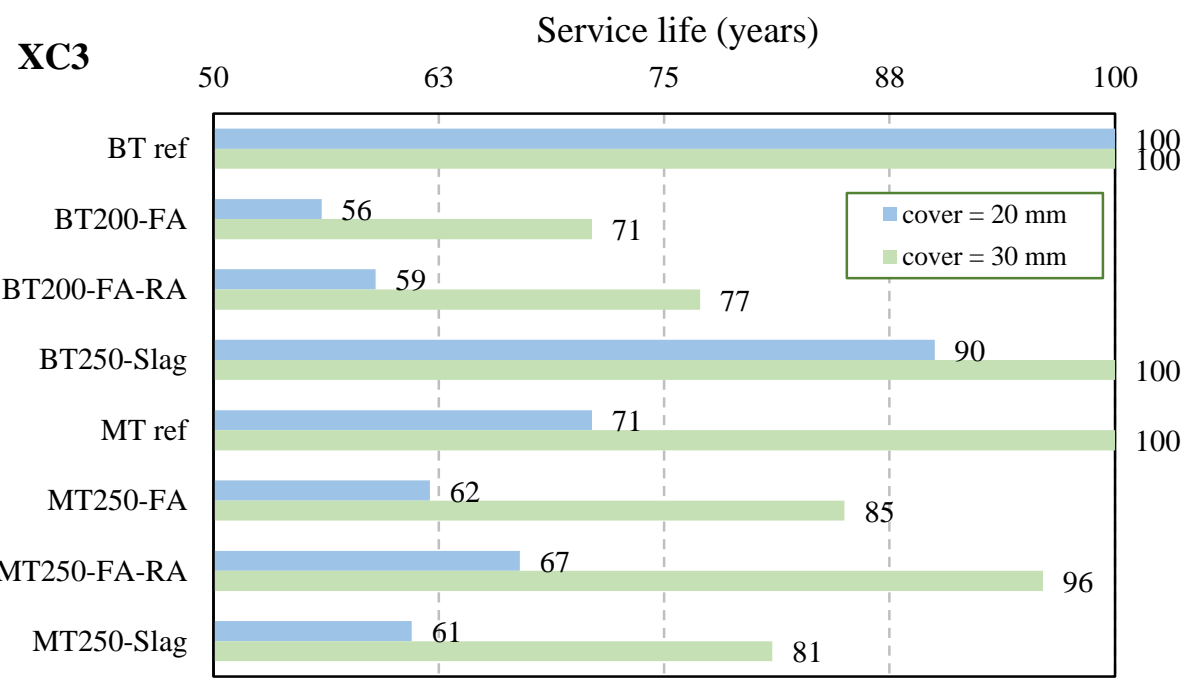

Figure 19. Service life expected for poles, class XC3.

It is clear that higher cement content provides a better performance regarding durability related with carbonation, since the two reference concrete mixtures had the highest service life. The results of Table 6 show that the service life expected for the poles, in most cases, was higher than 50 years, expect in environment XC4 (wet regime), meaning that the significant reduction in the amount of cement of the eco-efficient concrete can be compensated by using additions. The fly ash effect is similar in both types of concrete, the BT-dry consistency and the MT-plastic consistency, and the incorporation of the recycled aggregates does not influence the concrete performance. However, the use of ground electric furnace slag is more beneficial with BT250-slag than MT250-slag.

- Environmental exposure XS (chloride-induced corrosion)

For environments exposed to chlorides, the minimum propagation period, $t_{\mathrm{p}}$, also depends of several factors, and, according to LNEC E-465 [71], those values are 0 years for XS1 and XS3, and 40 years for exposure class XS2 [71]. The chloride diffusion coefficient, $\mathrm{D}\left(\mathrm{m}^{2} / \mathrm{s}\right)$, is determined for each developed concrete using Equation (6) and using the experimentally determined values of non-steady-state migration coefficients, $\mathrm{D}_{0}$ (Figure 15). Using Equations (6) and (7) [71], and defining the cover thickness, $X$, it is possible to determine the design period of initiation of poles made with each type of concrete and after the service life, $\mathrm{t}_{\mathrm{g}}$. In addition, using the same equations and defining the design period of initiation, $t_{i c}$, it is possible to determine the minimum concrete cover required to guarantee the resistance against the reinforcement corrosion induced by chlorides, $\mathrm{c}_{\min \text {,dur. For a }}$ service life equal to 50 years and considering the already mentioned reliability class (RC1), the design period of initiation, $t_{i c}$, can be determined using Equation (4) and is 100 years for XS1 and XS3, and 20 years for exposure class XS2.

$$
\begin{gathered}
D(t)=k D_{0} \times\left(t_{0} / t\right)^{n} \\
X=2 \times \xi \times \sqrt{D \times t_{i c}}
\end{gathered}
$$

where $\mathrm{k}$ is a factor that takes into account the curing conditions, the relative humidity and the temperature; $\mathrm{n}$ is a factor that considers the chloride diffusion decrease over time; $\mathrm{t}_{0}$ is the time of the experimental tests to evaluate $D_{0} ; t$ is the exposure time in days; $\xi$ is a parameter related with the concentration of chlorides in the binding paste; $\mathrm{X}$ is the cover. The minimum concrete cover required to protect the steel reinforcement against corrosion induced by chlorides, $c_{\text {min,dur }}$, is presented Table 7 and the prediction of service life, $t_{g}$, for 20 and $30 \mathrm{~mm}$ is presented in Figure 20 and Table 8. 
Table 7. Minimum cover, $\mathrm{c}_{\mathrm{min} \text {,dur, }}$ to resist corrosion induced by chlorides in electrical concrete poles.

\begin{tabular}{|c|c|c|c|c|}
\hline \multirow{3}{*}{ Concrete } & \multicolumn{4}{|c|}{ Minimum Cover, $c_{\min , \mathrm{dur}}(\mathrm{mm})$} \\
\hline & \multirow{2}{*}{$\mathrm{XS1}^{1}$} & \multicolumn{2}{|c|}{$X S 2^{2}$} & \multirow{2}{*}{$\mathrm{XS3}^{3}$} \\
\hline & & $1 \mathrm{~m}$ & $1.4-25 \mathrm{~m}$ & \\
\hline BTref & 40 & 45 & 50 & 97 \\
\hline BT200-FA & 17 & 21 & 24 & 46 \\
\hline BT200-FA-RA & 21 & 25 & 29 & 55 \\
\hline BT200-Poz & 15 & 18 & 21 & 40 \\
\hline MTref & 48 & 52 & 58 & 112 \\
\hline MT250-FA & 28 & 31 & 35 & 67 \\
\hline MT250-FA-RA & 31 & 35 & 39 & 74 \\
\hline MT250-Poz & 19 & 21 & 24 & 46 \\
\hline
\end{tabular}

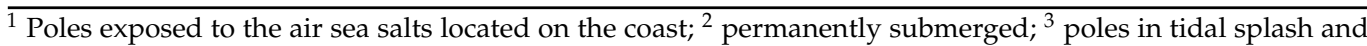
spray zones.

Table 8. Prediction of the service life, $t_{g}$, for different cover values (years), classes XS.

\begin{tabular}{|c|c|c|c|c|c|}
\hline \multirow{2}{*}{ Concrete } & \multirow{2}{*}{ Cover $(\mathrm{mm})$} & \multirow{2}{*}{ XS1 } & \multicolumn{2}{|c|}{ XS2 } & \multirow{2}{*}{ XS3 } \\
\hline & & & $1 \mathrm{~m}$ & $1.4-25 \mathrm{~m}$ & \\
\hline \multirow{2}{*}{ BTref } & 20 & 2 & 41 & 40 & 0 \\
\hline & 30 & 14 & 42 & 42 & 0 \\
\hline \multirow{2}{*}{ BT200-FA } & 20 & 91 & 48 & 45 & 1 \\
\hline & 30 & $>>100$ & 76 & 63 & 7 \\
\hline \multirow{2}{*}{ BT200-FA-RA } & 20 & 40 & 44 & 43 & 1 \\
\hline & 30 & $>>100$ & 59 & 52 & 3 \\
\hline \multirow{2}{*}{ BT250-Poz } & 20 & $>>100$ & 54 & 49 & 2 \\
\hline & 30 & $>>100$ & 101 & 79 & 14 \\
\hline \multirow{2}{*}{ MTref } & 20 & 1 & 40 & 40 & 0 \\
\hline & 30 & 6 & 41 & 41 & 0 \\
\hline \multirow{2}{*}{ MT250-FA } & 20 & 11 & 42 & 41 & 0 \\
\hline & 30 & 68 & 49 & 46 & 1 \\
\hline \multirow{2}{*}{ MT250-FA-RA } & 20 & 7 & 41 & 41 & 0 \\
\hline & 30 & 43 & 46 & 44 & 1 \\
\hline \multirow{2}{*}{ MT250-Poz } & 20 & 61 & 48 & 45 & 1 \\
\hline & 30 & $>>100$ & 75 & 64 & 8 \\
\hline
\end{tabular}

It is highly improbable that electric poles will be placed in tidal splash or spray zones or will be permanently submerged, but the results show that poles manufactured with these concretes should not be used in such zones. In environments with air-based sea salts, the reference concretes have a performance that is clearly worse than concretes with additions, which is reflected in the values of minimum cover, as well as in the service life expected. Among the concretes with additions, the behavior is relatively similar, showing that the pozzolanic additions can replace the cement dosage in the context of protection against corrosion induced by chlorides. It is also noted that, in this case, the incorporation of recycled aggregates slightly increases the minimum cover and decreases the expected service life. To assure a service life of 50 years for poles manufactured using these ecoefficient concretes, for both types of consistency, the cover requires ranges between 15 and $31 \mathrm{~mm}$, which are the values usually used in the production of this type of structures. 


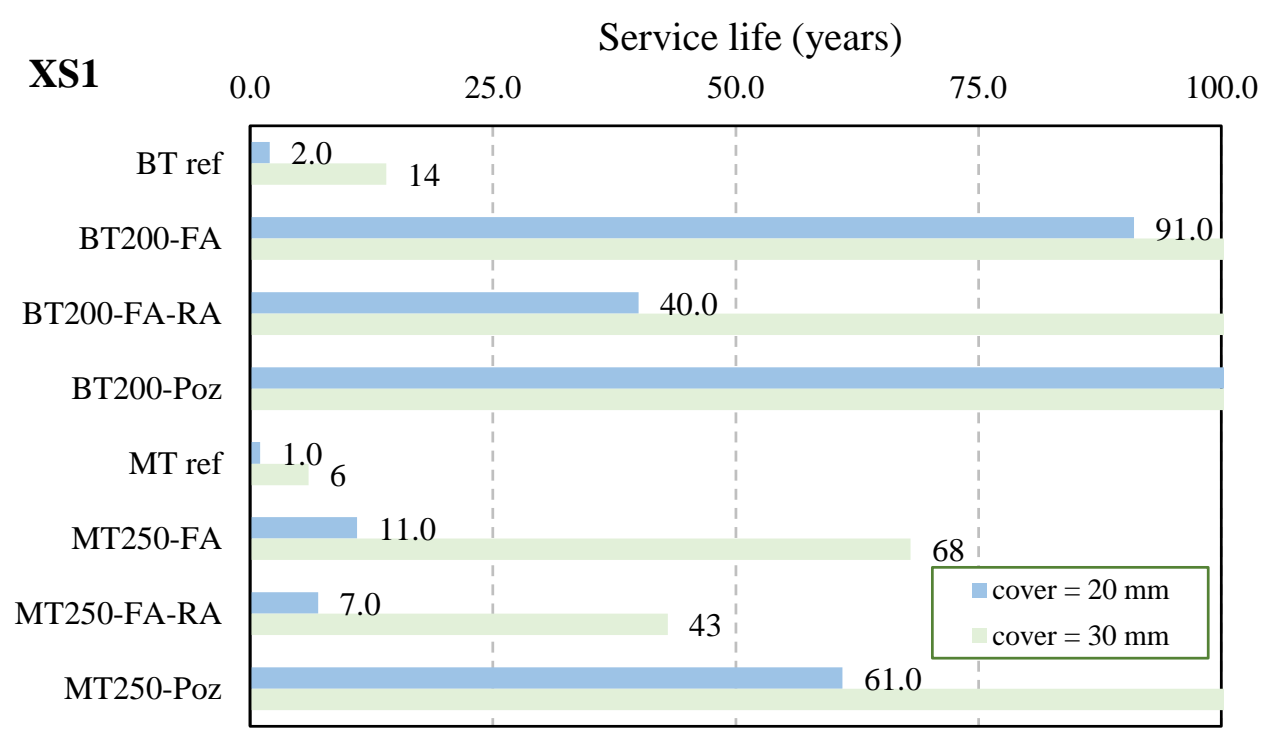

Figure 20. Service life expected for poles, class XS1.

\section{Conclusions}

The experimental study presented herein is focused on optimizing the mechanical and durability properties of concrete with low cement content, maximizing the compactness and combining the partial replacement of cement with a high content of fly ash, natural pozzolans, and electric furnace slags, with a $20 \%$ replacement of natural aggregates by recycled concrete aggregates. Two types of formulations were produced and characterized, BT (with dry consistency) and MT (with plastic consistency). The properties were compared to plain cement-based reference mixtures, commonly used in the prefabrication industry. Based on the analyses, the following conclusions are drawn:

1. Tensile splitting strength: (i) unlike the BT series, the addition of fly ash increases this strength by $31 \%$ in plastic concrete with natural aggregates, MT250-FA, and by $22 \%$ with recycled concrete aggregates, MT250-FA-RA, compared to the reference; (ii) the addition of recycled aggregates reduces this strength by $9 \%$ when compared to the same mixture with natural aggregates; (iii) the test results and the prediction values of EC2 are very similar, with a difference of about $10 \%$.

2. Flexural strength: (i) although cement reductions are high (from 30 to 50\%) in optimized mixtures, those with the addition of fly ash and slag show an increase of up to $27 \%$ in MT250-slag mixtures, compared to the respective reference, at 90 days; (ii) the inclusion of recycled concrete aggregates have practically no influence on this parameter; (iii) the prediction of EC2 has very similar values to those obtained in the tests, since this strength is directly related to the tensile splitting.

3. Compressive strength: (i) mixtures with additions tend to increase from 28 to 90 days, due to the pozzolanic effect and, despite the cement reduction, it increases up to $26 \%$ with fly ash and natural aggregates (MT250-FA), and up to $14 \%$ with fly ash and natural and recycled aggregates (MT250-FA-RA), at 90 days, in comparison to the reference; (ii) the hardening curve of EC2 prediction has an R (rapid) evolution at early ages in concretes without pozzolanic additions, contrary to the curve of mixtures with pozzolanic additions, which has an S (slow) beginning, but a more pronounced evolution at later ages.

4. Young's modulus: (i) adding supplementary cementitious materials (pozzolan, slag and fly ash) to the concrete increases this parameter, mainly in the case of pozzolans addition, that lead to increases of $11 \%$ and $13 \%$, for BT200-Poz and MT250-Poz, respectively, comparing to the references; (ii) as expected, the inclusion of recycled concrete aggregates reduces this parameter, due to their lower stiffness; (iii) the test 
results are always higher than those predicted with the codes, with increases of up to $26 \%$ for the mixture with the addition of pozzolans, BT250-Poz.

5. Capillary water absorption and water penetration under pressure: (i) in dry BT concrete, the high content of fly ash addition ( $50 \%$ of cement replacement rate) combined with high compactness is beneficial, since it presents the same capillarity as the reference; (ii) concrete with plastic consistency-MT, where $30 \%$ of the cement was replaced by fly ash addition, shows even more positive results, absorbing $44 \%$ less capillary water than the reference; (iii) the inclusion of recycled concrete aggregates is also beneficial, since it presents similar or lower capillarity values as the mixtures with only natural aggregates; (iv) the addition of fly ash is beneficial to reduce water penetration under pressure, absorbing $65 \%$ less water than the reference and the recycled aggregates have little influence on this parameter.

6. Carbonation resistance: (i) the cement dosage has an important influence on reducing the carbonation depth, the reference mixtures being those with less carbonation; (ii) in $\mathrm{BT}$, high compactness combined with slag addition proved to be an efficient mixture regarding this parameter, since despite having high cement replacement, BT250-slag presents only $46 \%$ more carbonation depth than the reference, instead of $120 \%$ for the mixtures using fly ash; (iii) MT mixtures with fly ash additions have similar effects in reducing carbonation compared to the reference, with or without recycled concrete aggregates; (iv) in MT series, slag addition, after an initial benefit, also tends to change the effect at older ages.

7. Service life of structures exposed to carbonation: (i) higher cement dosages promote longer lifetimes, as the references present the highest values of this parameter; (ii) in XC2 environments, a service life of 100 years is ensured for all mixtures with a 15-mm cover, while in $\mathrm{XC} 3$ environments a 50 year service life is ensured for all mixtures with a 20-mm cover; in the XC4 environment, the same service life is, in general, ensured with a cover of $20 \mathrm{~mm}$; (iv) the incorporation of recycled aggregates has a small but positive influence on concrete performance.

8. Chloride diffusion coefficient: (i) mixtures with type II additions show the greatest influence of pozzolanic effects and the corresponding maturity of the matrixes with age; (ii) the addition of fly ash is very advantageous for increasing the resistance to chloride migration, reducing the chloride coefficient up to $80 \%$, in MT250-FA, at 90 days; (ii) natural pozzolan addition is also very beneficial regarding chloride resistance, presenting $\mathrm{D}_{0}$ values of $81 \%$ below the reference, in MT250-Poz; (iii) naturally, the inclusion of recycled concrete aggregates slightly increase the $\mathrm{D}_{0}$ coefficient; (iv) all optimized mixtures are rated with "very/extremely high" chloride penetration resistance.

9. Electrical resistivity of the concrete surface: (i) since this test allows a quick assessment and prediction of chloride migration, this evaluation proves to be accurate, revealing the same trend in the chloride migration test and considering the high correlation between both results; (ii) concrete with the addition of fly ash shows the highest values of this parameter, followed by concrete with the addition of pozzolans; (iii) all mixtures tend to stabilize after around 300 days.

10. Service life of structures exposed to chloride ions: (i) pozzolanic additions highly influence the resistance to chloride penetration, which is proved by the results of mixtures with fly ash and pozzolans; (ii) to assure a service life of 50 years, both in the BT and MT series, the cover required ranges between 15 and $31 \mathrm{~mm}$; (iii) the incorporation of recycled aggregates slightly increases the minimum cover and decreases the expected service life.

Finally, it is concluded that eco-efficient concrete mixtures designed with high compactness, low cement content, and a high replacement rate (up to 50\%) of cement through specific additions (fly ash, natural pozzolans and electric furnace slags), combined with $20 \%$ recycled concrete aggregates, still generally present improved mechanical properties. Regarding durability, depending on the exposure conditions related to corrosion risk in- 
duced by chloride ions or by carbonation, these concrete mixtures can lead to significant improvements in terms of chloride resistance and to a minor influence, or a slight decrease, in carbonation resistance, even though they have a generally long service life.

Author Contributions: Conceptualization, H.C.; formal analysis, E.S., A.A. and R.d.C.; investigation, H.C.; methodology, H.C. and R.d.C.; project administration, H.C. and E.J.; supervision, E.J.; validation, H.C. and R.d.C.; writing—original draft, E.S. and A.A.; writing—review and editing, H.C., R.d.C. and E.J. All authors have read and agreed to the published version of the manuscript.

Funding: This work is co-financed by the European Regional Development Fund (ERDF), through the partnership agreement Portugal2020-Operational Program for Competitiveness and Internationalization (COMPETE2020), under the project POCI-01-0247-FEDER-033523 “POSTEJO 4.0: Inovação para a diversificação e a exportação".

Institutional Review Board Statement: Not applicable.

Informed Consent Statement: Not applicable.

Data Availability Statement: Data available on request due to restrictions eg privacy or ethical. The data presented in this study are available on request from the corresponding author. The data are not publicly available due to confidentiality restrictions of the funded project.

Acknowledgments: Authors acknowledge the Polytechnic Institute of Coimbra, ISEC, for providing the facilities and all necessary resources to perform the present study and the companies Postejo, Cimpor, Sarendur, Sabril, Omya, Harsco, Basf and Sika, for their support through material supply.

Conflicts of Interest: The authors declare no conflict of interest. The funders had no role in the design of the study; in the collection, analyses, or interpretation of data; in the writing of the manuscript, or in the decision to publish the results.

\section{References}

1. The European Cement Association (CEMBUREAU). Activity Report 2019. 2020. Available online: https://cembureau.eu/media/ clkdda45/activity-report-2019.pdf (accessed on 23 June 2021).

2. The European Cement Association (CEMBUREAU). Cementing the European Green Deal-The Roadmap. 2020. Available online: https://cembureau.eu/media/kuxd32gi/cembureau-2050-roadmap_final-version_web.pdf (accessed on 23 June 2021).

3. Robalo, K.; Costa, H.; Carmo, R.d.; Júlio, E. Experimental development of low cement content and recycled construction and demolition waste aggregates concrete. Constr. Build. Mater. 2021, 273, 121680. [CrossRef]

4. Tam, V.W.Y.; Soomro, M.; Evangelista, A.C.J. A review of recycled aggregate in concrete applications (2000-2017). Constr. Build. Mater. 2018, 172, 272-292. [CrossRef]

5. Proske, T.; Hainer, S.; Rezvani, M.; Graubner, C.A. Eco-friendly concretes with reduced water and cement content-Mix design principles and application in practice. Constr. Build. Mater. 2014, 67, 413-421. [CrossRef]

6. Robalo, K.; Soldado, E.; Costa, H.; Carmo, R.D.; Alves, H.; Júlio, E. Efficiency of cement content and of compactness on mechanical performance of low cement concrete designed with packing optimization. Constr. Build. Mater. 2021, 266, 121077. [CrossRef]

7. De Grazia, M.T.; Sanchez, L.F.M.; Romano, R.C.O.; Pileggi, R.G. Investigation of the use of continuous particle packing models (PPMs) on the fresh and hardened properties of low-cement concrete (LCC) systems. Constr. Build. Mater. 2019, 195, 524-536. [CrossRef]

8. Fennis, S.A.A.M.; Walraven, J.C. Using particle packing technology for sustainable concrete mixture design. Heron 2012, 57, 73-101.

9. Faury, J. Le Bêton: Influence de ses Constituants Inertes. Règles à Adopter Pour sa Meilleure Composition. Sa Confection et son Transport sur les Chantiers, 3rd ed.; Dunod: Paris, France, 1958.

10. Fennis, S.A.A.M.; Walraven, J.C.; den Uijl, J.A. The use of particle packing models to design ecological concrete. Heron 2009, 54, 183-202.

11. Costa, H.; Alves, H.; Freitas, E.; Júlio, E. Mechanical performance of concrete with low cement dosage. In Proceedings of the National Meeting of Structural Concrete-BE2016, Coimbra, Portugal, 2-4 November 2016. (In Portuguese).

12. Fennis, S.A.A.M.; Walraven, J.C.; den Uijl, J.A. Compaction-interaction packing mode: Regarding the effect of fillers in concrete mixture design. Mater. Struct. Constr. 2013, 46, 463-478. [CrossRef]

13. Müllera, H.S.; Breinera, R.; Moffatta, J.S.; Haista, M. Design and properties of sustainable concrete. Procedia Eng. 2014, 95, $290-304$. [CrossRef]

14. Björnström, J.; Chandra, S. Effect of superplasticizers on the rheological properties of cements. Mater. Struct. Constr. 2003, 36, 685-692. [CrossRef] 
15. Mehta, P.K. High-performance, high-volume fly ash concrete for sustainable development. In Proceedings of the International Workshop on Sustainable Development and Concrete Technology; Iowa State University: Ames, IA, USA, 2004; pp. 3-14.

16. Bentz, D.P.; Hansen, A.S.; Guynn, J.M. Optimization of cement and fly ash particle sizes to produce sustainable concretes. Cem. Concr. Compos. 2011, 33, 824-831. [CrossRef]

17. Teixeira, E.; Branco, F.; Camões, A. Eco-efficient concrete study through the use of biomass fly ash. In Proceedings of the 3rd Luso-Brazilian Congress on Sustainable Construction Materials, Coimbra, Portugal, 14-16 February 2018. (In Portuguese).

18. Nasvik, J. Sustainable concrete structures-How to use concrete for sustainable purposes. Concr. Constr. 2013, 2, 765-780. Available online: https://www.concreteconstruction.net/business/management/sustainable-concrete-structures_o (accessed on 23 June 2021).

19. Jiang, L.H.; Malhotra, V.M. Reduction in water demand of non-air-entrained concrete incorporating large volumes of fly ash. Cem. Concr. Res. 2000, 30, 1785-1789. [CrossRef]

20. Bogas, J.A.; Real, S. A review on the carbonation and chloride penetration resistance of structural lightweight aggregate concrete. Materials 2019, 12, 3456. [CrossRef] [PubMed]

21. Proske, C.G.T.; Hainer, S.; Rezvani, M. Handbook of Low Carbon Concrete; Elsevier: Amsterdam, The Netherlands, 2017.

22. Saha, A.K. Effect of class F fly ash on the durability properties of concrete. Sustain. Environ. Res. 2018, 28, 25-31. [CrossRef]

23. Bentz, D.P.; Sato, T.; de la Varga, I.; Weiss, W.J. Fine limestone additions to regulate setting in high volume fly ash mixtures. Cem. Concr. Compos. 2012, 34, 11-17. [CrossRef]

24. Pacheco, J.; de Brito, J.; Chastre, C.; Evangelista, L. Experimental investigation on the variability of the main mechanical properties of concrete produced with coarse recycled concrete aggregates. Constr. Build. Mater. 2019, 201, 110-120. [CrossRef]

25. Tamayo, P.; Pacheco, J.; Thomas, C.; de Brito, J.; Rico, J. Mechanical and durability properties of concrete with coarse recycled aggregate produced with electric arc furnace slag concrete. Appl. Sci. 2020, 10, 216. [CrossRef]

26. Thomas, C.; de Brito, J. Corinaldesi, Special issue high-performance eco-efficient concrete. Appl. Sci. 2021, 11, 1163. [CrossRef]

27. Yang, K.H.; Chung, H.S.; Ashour, A.F. Influence of type and replacement level of recycled aggregates on concrete properties. ACI Mater. J. 2008, 105, 289-296. [CrossRef]

28. Malešev, M.; Radonjanin, V.; Draganić, S.; Šupić, S.; Laban, M. Influence of fly ash and decreasing water-powder ratio on performance of recycled aggregate concrete. J. Croat. Assoc. Civ. Eng. 2017, 69, 811-820. [CrossRef]

29. Rahal, K. Mechanical properties of concrete with recycled coarse aggregate. Build. Environ. 2007, 42, 407-415. [CrossRef]

30. To, N.; Michel, J.; Thierry, T.; Ignjatovi, I. Toward a codified design of recycled aggregate concrete structures: Background for the new fib Model Code 2020 and Eurocode 2. Struct. Concr. 2020, 1-23. [CrossRef]

31. E 471. Guide for Using Coarse Recycled Aggregates in Hydraulic Binder Concrete; National Laboratory of Civil Engineering (LNEC): Lisbon, Portugal, 2009. (In Portuguese)

32. Silva, R.V.; de Brito, J.; Neves, R.; Dhir, R. Prediction of chloride ion penetration of recycled aggregate concrete. Mater. Res. 2015, 18, 427-440. [CrossRef]

33. Bogas, J.A.; Gomes, A. Non-steady-state accelerated chloride penetration resistance of structural lightweight aggregate concrete. Cem. Concr. Compos. 2015, 60, 111-122. [CrossRef]

34. Andrade, C.; Prieto, M.; Tanner, P.; Tavares, F.; D'Andrea, R. Testing and modelling chloride penetration into concrete. Constr. Build. Mater. 2013, 39, 9-18. [CrossRef]

35. Vyas, P.C.M.; Pitroda, P.J. Fly Ash and Recycled Coarse Aggregate in Concrete: New Era for Construction Industries-A Literature Review. Int. J. Eng. Trends Technol. 2013, 4, 1781-1787.

36. Wu, P.; Wang, X.; Huang, T.; Zhang, W. Permeability and prediction of free chloride ion in recycled aggregate concrete with fly ash. Int. J. Electrochem. Sci. 2014, 9, 3513-3535.

37. Neville, A. Chloride attack of reinforced concrete: An overview. Mater. Struct. 1995, 28, 63-70. [CrossRef]

38. Richardson, M.G. Fundamentals of Durable Reinforced Concrete; Taylor \& Francis: London, UK, 2002. [CrossRef]

39. Du, Y.G.; Clark, L.A.; Chan, A.H.C. Residual capacity of corroded reinforcing bars. Mag. Concr. Res. 2005, 57, 135-147. [CrossRef]

40. Gjørv, O.E. Durability of concrete structures. Arab. J. Sci. Eng. 2011, 36, 151-172. [CrossRef]

41. Torres-Luque, M.; Bastidas-Arteaga, E.; Schoefs, F.; Sánchez-Silva, M.; Osma, J.F. Non-destructive methods for measuring chloride ingress into concrete: State-of-the-art and future challenges. Constr. Build. Mater. 2014, 68, 68-81. [CrossRef]

42. Zambon, I.; Ariza, M.P.S.; Matos, J.C.; Strauss, A. Value of information (VoI) for the chloride content in reinforced concrete bridges. Appl. Sci. 2020, 10, 567. [CrossRef]

43. Robalo, K.; Soldado, E.; Costa, H.; Carvalho, L.; do Carmo, E.R.J. Durability and time-dependent properties of low-cement concrete. Materials 2020, 13, 3583. [CrossRef] [PubMed]

44. Coutinho, J.S. Improving the Durability of Concrete by Treating Formwork, FEUP ed.; FEUP: Porto, Portugal, 2005. (In Portuguese)

45. Ngala, V.T.; Page, C.L. Effects of carbonation on pore structure and diffusional properties of hydrated cement pastes. Cem. Concr. Res. 1997, 27, 995-1007. [CrossRef]

46. Shah, V.; Bishnoi, S. Analysis of Pore Structure Characteristics of Carbonated Low-Clinker Cements. Transp. Porous Media 2018, 124, 861-881. [CrossRef]

47. Jones, M.R.; Dhir, R.K.; Newlands, M.D.; Abbas, A.M.O. Study of the CEN test method for measurement of the carbonation depth of hardened concrete. Mater. Struct. Constr. 2000, 33, 135-142. [CrossRef] 
48. Soldado, E.; Antunes, A.; Costa, H.; do Carmo, E.R.J. Optimization of cementitious matrixes with low cement and different additions to enhance the mechanical and durability properties. In Proceedings of the 74th RILEM Annual Week \& 40th Cement and Concrete Science Conference, University of Sheffield, Online, 31 August-4 September 2020.

49. Fly Ash for Concrete. Part 1: Definition, Specifications and Conformity Criteria; EN 450-1:2005+A1; European Committee for Standardization-CEN: Brussels, Belgium, 2008.

50. Lourenço, J.; Júlio, E.; Maranha, P. Expanded Clay Lightweight Aggregate Concrete; APEB: Lisbon, Portugal, 2004. (In Portuguese)

51. Costa, H. Structural Concretes of Light Aggregates. Applications in Prefabrication and Reinforcement of Structures. Ph.D. Thesis, University of Coimbra, Coimbra, Portugal, 2012. (In Portuguese).

52. Testing Fresh Concrete-Part 2: Slump-Test; EN 12350-2; European Committee for Standardization-CEN: Brussels, Belgium, 2009.

53. Testing Fresh Concrete-Part 3: Vebe; EN 12350-3; European Committee for Standardization—CEN: Brussels, Belgium, 2009.

54. Testing Fresh Concrete-Part 4: Degree of Compactability; EN 12350-4; European Committee for Standardization-CEN: Brussels, Belgium, 2009.

55. Testing Fresh Concrete—Part 7: Air Content. Pressure Methods; EN 12350-7; European Committee for Standardization-CEN Brussels, Belgium, 2009.

56. Testing Hardened Concrete-Part 3: Compressive Strength of Test Specimens; EN 12390-3; European Committee for StandardizationCEN: Brussels, Belgium, 2009.

57. Testing Hardened Concrete—Part 6: Tensile Splitting Strength of Test Specimens; EN 12390-6; European Committee for StandardizationCEN: Brussels, Belgium, 2003.

58. Testing Hardened Concrete-Part 5: Flexural Strength of Test Specimens; EN 12390-5; European Committee for Standardization-CEN: Brussels, Belgium, 2009.

59. E 397, Hardened Concrete: Determination of the Modulus of Elasticity of Concrete in Compression; National Laboratory of Civil Engineering (LNEC): Lisbon, Portugal, 1993. (In Portuguese)

60. E 393, Concrete: Determination of the Absorption of Water Through Capillarity; National Laboratory of Civil Engineering (LNEC): Lisbon, Portugal, 1993. (In Portuguese)

61. Testing Hardened Concrete-Part 8: Depth of Penetration of Water Under Pressure; EN 12390-8; European Committee for Standardization-CEN: Brussels, Belgium, 2009.

62. E 391, Concrete: Determination of Carbonation Resistance; National Laboratory of Civil Engineering (LNEC): Lisbon, Portugal, 1993. (In Portuguese)

63. E 463, Concrete: Determination of Diffusion Coefficient of Chlorides from Non-Steady-State Migration Test; National Laboratory of Civil Engineering (LNEC): Lisbon, Portugal, 2004. (In Portuguese)

64. T 358, Surface Resistivity Indication of Concrete's Ability to Resist Chloride Ion Penetration; AASHTO: Washington, DC, USA, 2015.

65. Eurocode 2-Design of Concrete Structures. Part 1-1: General Rules and Rules for Buildings; EN 1992-1-1; European Committee for Standardization-CEN: Brussels, Belgium, 2010.

66. CEB-FIP Comite Euro-International du Beton (FIB). Model Code 2010; FIB: Lausanne, Switzerland, 2010.

67. Beltrán, M.G.; Barbudo, A.; Agrela, F.; Galvín, A.P.; Jiménez, J.R. Effect of cement addition on the properties of recycled concretes to reach control concretes strengths. J. Clean. Prod. 2014, 79, 124-133. [CrossRef]

68. Limbachiya, M.; Meddah, M.S.; Ouchagour, Y. Use of recycled concrete aggregate in fly-ash concrete. Constr. Build. Mater. 2012, 27, 439-449. [CrossRef]

69. Browne, R.D. Field Investigations: Site \& Laboratory Tests: Maintenance, Repair and Rehabilitation of Concrete Structures; CEEC: Lisbon, Portugal, 1991.

70. Kurda, R.; de Brito, J.; Silvestre, J.D. Water absorption and electrical resistivity of concrete with recycled concrete aggregates and fly ash. Cem. Concr. Compos. 2019, 95, 169-182. [CrossRef]

71. E 465, Concrete. Methodology for Estimating the Concrete Performance Properties Allowing to Comply with the Design Working Life of the Reinforced or Prestressed Concrete Structures under the Environmental Exposures XC and XS; National Laboratory of Civil Engineering (LNEC): Lisbon, Portugal, 2007. (In Portuguese) 